\title{
Low Temperature Irradiation Embrittlement of Reactor Pressure Vessel Steels
}

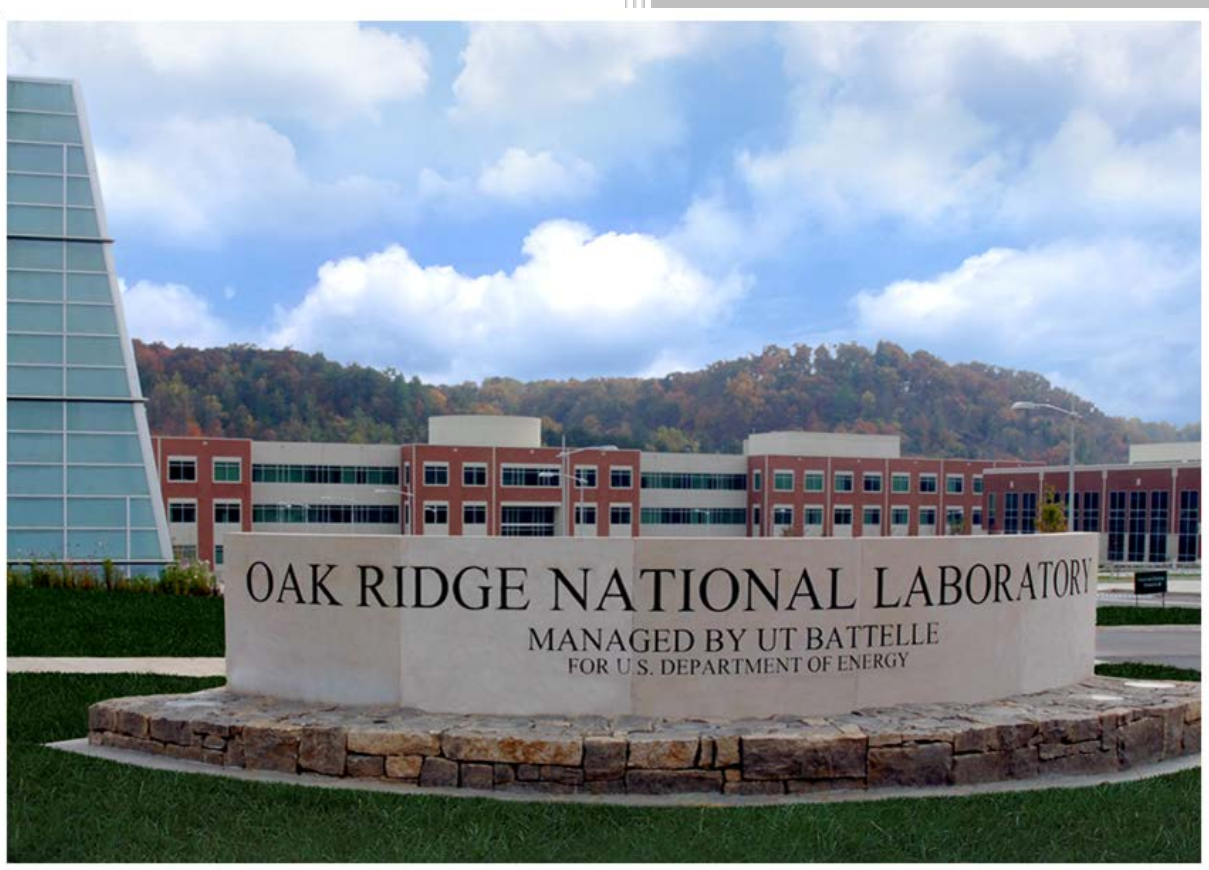

Jy-An John Wang

Approved for public release. Distribution is unlimited. 


\title{
DOCUMENT AVAILABILITY
}

Reports produced after January 1, 1996, are generally available free via US Department of Energy (DOE) SciTech Connect.

Website http://www.osti.gov/scitech/

Reports produced before January 1, 1996, may be purchased by members of the public from the following source:

\author{
National Technical Information Service \\ 5285 Port Royal Road \\ Springfield, VA 22161 \\ Telephone 703-605-6000 (1-800-553-6847) \\ TDD 703-487-4639 \\ Fax 703-605-6900 \\ E-mail info@ntis.gov \\ Website http://www.ntis.gov/help/ordermethods.aspx
}

Reports are available to DOE employees, DOE contractors, Energy Technology Data Exchange representatives, and International Nuclear Information System representatives from the following source:

Office of Scientific and Technical Information

PO Box 62

Oak Ridge, TN 37831

Telephone 865-576-8401

Fax 865-576-5728

E-mail reports@osti.gov

Website http://www.osti.gov/contact.html

This report was prepared as an account of work sponsored by an agency of the United States Government. Neither the United States Government nor any agency thereof, nor any of their employees, makes any warranty, express or implied, or assumes any legal liability or responsibility for the accuracy, completeness, or usefulness of any information, apparatus, product, or process disclosed, or represents that its use would not infringe privately owned rights. Reference herein to any specific commercial product, process, or service by trade name, trademark, manufacturer, or otherwise, does not necessarily constitute or imply its endorsement, recommendation, or favoring by the United States Government or any agency thereof. The views and opinions of authors expressed herein do not necessarily state or reflect those of the United States Government or any agency thereof. 
Materials Science and Technology Division

\title{
Low Temperature Irradiation Embrittlement of Reactor Pressure Vessel Steels
}

\author{
Jy-An John Wang
}

Date Published: May 2011

\author{
Prepared by \\ OAK RIDGE NATIONAL LABORATORY \\ P.O. Box 2008 \\ Oak Ridge, Tennessee 37831-6285 \\ managed by \\ UT-Battelle, LLC \\ for the \\ U.S. DEPARTMENT OF ENERGY \\ under contract DE-AC05-00OR22725
}




\section{CONTENTS}

Page

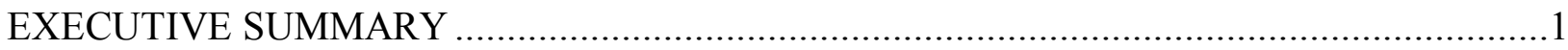





2. TASK 1: Data Collection to Match that Published in 1994 for the HFIR RPV Trend Curve ....3

2.1 Trend Curve Includes High Dose Data.....................................................................4

2.2 Low Temperature RPV Embrittlement Predictive Curve w/o High Dose Data .................8

2.3 Comparison of Low Temperature RPV Embrittlement Trend Curves w/ and w/o High

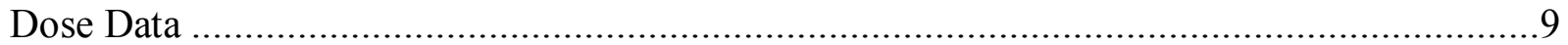

2.4 Hawthorne Low Temperature Data ...................................................................... 10

2.5 Comparison of Trend Curves w/ All or w/ only A212B Data from Hawthorne's Data ......11

3. TASK 2: Additional New Embrittlement Data Associated with A212B Steels.....................12

3.1 New NDTT Shift Data for A212B Steel.................................................................12

3.2 The Detailed Investigation of the New Embrittlement Data ........................................12

3.3. Comparison of Embrittlement Trends between New Data and A212B CMM Data..........15

4. TASK 3: The Adjustment of NDTT Shifts for A212B CMM Test Reactor Data...................17

4.1 Irradiation Temperature Effect.............................................................................17

4.2 The Shift Adjustments of A212B CMM Data to Project Embrittlement at Lower

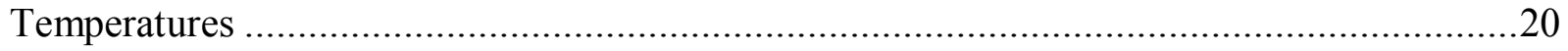

4.3 The Low Irradiation Temperature RPV Embrittlement Trend Curve ..............................23

4.4 Comparison of the Low Irradiation Temperature RPV Steels Embrittlement Trend Curve



5. SURVEILLANCE SPECIMEN IRRADIATION TEMPERATURES ...........................25

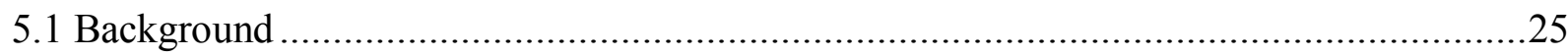

5.2 Approach................................................................................................26

5.2.1 Task I: Neutronic Analysis-Calculation of energy deposition in the surveillance

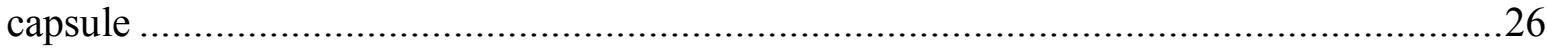

5.2.2 Task II: Thermo-Mechanical Analysis-Evaluation of the temperature variation in the



5.3 Issue Associated with HFIR Surveillance Capsule Temperature..............................27

6. SMALL SPECIMEN TECHNOLOGY IN APPLYING TO REACTOR RPV

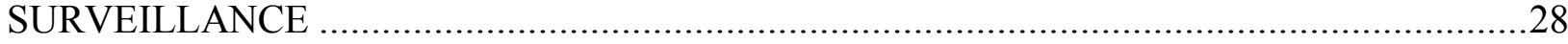

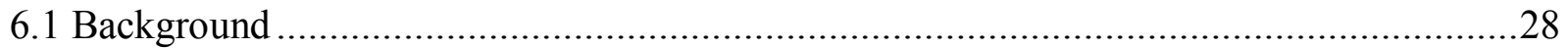

6.2 The "Local Approach" to Cleavage Fracture...............................................................29

6.3 Local Approach in Application to Master Curve Application ........................................29

6.4 Spiral Notch Torsion Fracture Toughness Test and Its Application to Small Specimens and

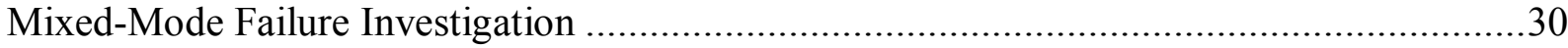



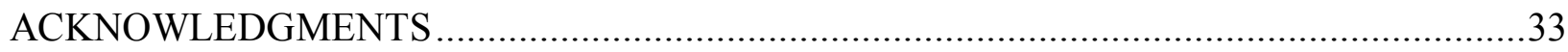







\section{LIST OF FIGURES}

Figure

Page

Figure 1 HFIR RPV steel trend curve fit from ref. [1], including dpa $>0.1$ data. .4

Figure 2 Low temperature RPV steel irradiation embrittlement trend curve fit, including dpa $>0.1$ data. 9

Figure 3 Comparison of the low temperature irradiation embrittlement trend curves developed with and without the high dose data, dpa $>0.1$.

Figure 4 Trend curves developed w/o dpa $>0.1$ and only retained A212B data from Hawthorne's data. 10

Figure 5 Comparison of low temperature RPV embrittlement trend curves developed with all data or with only A212B data from Hawthorne low temperature database.

Figure 6 Test reactor data from A212B CMM data, Hawthorne A212B data, and Porter A212B data. All are standard Charpy samples, except noted in the figure legend.........................14

Figure 7 The embrittlement trend curves of test reactor data from A212B CMM data, Hawthorne A212B data, and the updated/adjusted A212B Porter data. All the data shown in the figure are standard Charpy samples, except noted in the figure legends.

Figure 8 Irradiation temperature effect demonstrated by HSST03 CMM materials. .................19

Figure 9 Effect of Irradiation Temperature on Charpy Transition Increase of A212B Steel.......20

Figure 10 Comparison of irradiation temperature effect for A212B test reactor data...............22

Figure 11 The low irradiation temperature RPV steels embrittlement trend curve with the consideration of irradiation temperature effect.

Figure 12 Comparison of the low irradiation temperature RPV embrittlement trend curve and that developed in 1994.

Figure 13 Tested SNTT metal specimens (A533B1) showing specimen miniaturization............31

Figure 14 Fractured 7475-T7351 aluminum SNTT sample reveals uniform crack front............31

Figure 15 Fractured SNTT Gleeble samples..............................................................32 



\section{LIST OF TABLES}

Table

Page

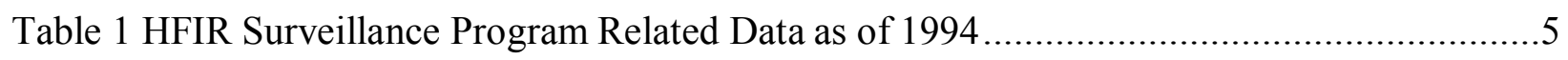

Table 2 Low Temperature Data $\left(\right.$ Temp. $<93^{\circ} \mathrm{C}$ ) from Steele and Hawthorne [5]......................6

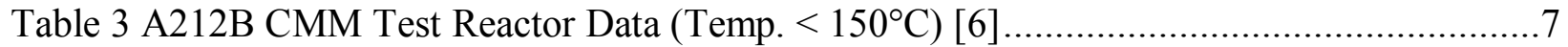

Table 4 Additional Embrittlement Data for A212B Steels .................................................14

Table 5 Standard Charpy Data from Porter's Data for A212B Steels ......................................14

Table 6 Sub-size Charpy Data from Porter's Data for A212B Steels ....................................15



Table 8 The adjusted $\mathrm{A} 212 \mathrm{~B}$ test reactor data, to project temperature from $150^{\circ} \mathrm{C}$ to $50^{\circ} \mathrm{C} \ldots \ldots . .21$

Table 9 The adjusted Hawthorne's A212B data, to project temperature from $93^{\circ} \mathrm{C}$ to $50^{\circ} \mathrm{C} \ldots . .22$ 


\section{EXECUTIVE SUMMARY}

A study of low temperature irradiation embrittlement of reactor pressure vessel (RPV) steels was carried out with three major tasks, as described below:

(1) Data collection to match that used in HFIR RPV steel embrittlement trend curve published in 1994's Journal of Nuclear Material, by Remec et. al. (Ref. 1),

(2) New embrittlement data of A212B steel that are not included in 1994's HFIR embrittlement trend curve development, and

(3) The adjustment of nil-ductility-transition temperature (NDTT) shift data with consideration of the irradiation temperature effect.

The main findings are the following:

(1) A total of 74 data points, used in the 1994 HFIR embrittlement trend curve development, was identified. It includes three main data sources, namely, (1) Hawthorne's data, (2) A212B test reactor data, and (3) HFIR RPV integrity surveillance program related data. The governing equation of this embrittlement trend curve was estimated and is written as below.

$\Delta \operatorname{NDTT}\left({ }^{\circ} \mathrm{C}\right)=31.3 \log (x)^{2}+233.5 \log (x)+448.7$, with a $2-\sigma$ uncertainty of $33.4^{\circ} \mathrm{C}$, where parameter $x$ is total dpa.

(2) 17 Charpy NDTT shift data of A212B materials, with irradiation temperature less than $93^{\circ} \mathrm{C}\left(200^{\circ} \mathrm{F}\right)$, were identified. However, these data show a significant different trend compared to the trend revealed from the $\mathrm{A} 212 \mathrm{~B}$ test reactor data. Thus, the decision was made to not include these data into the low temperature irradiation embrittlement study.

(3) An increase of $17.4{ }^{\circ} \mathrm{C}$ was applied to the A212B test reactor data with a $150^{\circ} \mathrm{C}$ irradiation temperature, to compensate for the $50^{\circ} \mathrm{C}$ irradiation temperature of HFIR. A total of 59 data points was used in developing a low temperature irradiation embrittlement predictive curve. The governing equation of this curve with the consideration of the temperature adjustment is written as below.

$\Delta \operatorname{NDTT}\left({ }^{\circ} \mathrm{C}\right)=23.85 \log (x)^{2}+203.3 \log (x)+434.7$, with $2-\sigma$ uncertainty of $34.6^{\circ} \mathrm{C}$

This predictive curve has a higher embrittlement rate compared to that of the trend curve developed in 1994. 


\section{ABSTRACT}

The project on irradiation embrittlement of reactor pressure vessel (RPV) steels irradiated at low temperatures $\left(<93^{\circ} \mathrm{C}\right)$ was carried out with three major tasks; (1) data collection to match that used in the HFIR steel embrittlement trend curve study published in 1994 by Remec et. al, (2) new embrittlement data of A212B steel that are not included in the earlier HFIR RPV trend curve, and (3) the adjustment of nil-ductility-transition temperature (NDTT) shift data with consideration of the irradiation temperature effect. A low temperature RPV steel irradiation embrittlement predictive curve was developed, as described below.

$\Delta \operatorname{NDTT}\left({ }^{\circ} \mathrm{C}\right)=23.85 \log (x)^{2}+203.3 \log (x)+434.7$,

with $2-\sigma$ uncertainty of $34.6^{\circ} \mathrm{C}$, where parameter $x$ is total dpa.

The low temperature RPV steel irradiation embrittlement curve has a higher embrittlement rate compared to that of the HFIR trend curve developed in 1994.

Keywords - embrittlement prediction, nil-ductility-transition temperature, total dpa, radiation embrittlement, reactor pressure vessel steel, HFIR 


\section{INTRODUCTION}

The study of reactor pressure vessel (RPV) steels irradiated at low temperatures was carried out with three major tasks; (1) data collection to match that used in the HFIR RPV steel embrittlement trend curve study published in 1994 by Remec et. al [1], (2) new embrittlement data of A212B steel that are not included in the earlier 1994 HFIR trend curve, and (3) the adjustment of nil-ductility-transition temperature (NDTT) shift data with consideration of the irradiation temperature effect, as described below.

\section{TASK 1: Data Collection to Match that Published in 1994 for the HFIR RPV Trend Curve}

The main objective of this task is to:

Assemble the test reactor embrittlement data for A212B steel to reproduce the trend curve that was presented in Fig. 8 of the paper "Effects of gamma-induced displacements on HFIR pressure vessel materials." published in the 1994 Journal of Nuclear Materials.

Based on the test reactor data collected from the open literatures, a reproduction of the HFIR trend curve was generated, shown in Fig. 1. The embrittlement data (in term of the Charpy transition temperature shift vs. dpa) were originated from several sources, as described below:

(1) HFIR surveillance data and Oak Ridge Research Reactor (ORR) test reactor data [1-3], with irradiation temperature $\sim 50^{\circ} \mathrm{C}$, where A212B, A350 LF3, and A105 II data were obtained from irradiations at a fast flux $(>1 \mathrm{MeV})$ of $1.0 \mathrm{E}+13 \mathrm{n} / \mathrm{cm}^{2} \mathrm{~s}$. This is about 4-orders of magnitude higher fast neutron flux than HFIR surveillance data, with a fast flux $\sim 1.0 \mathrm{E}+8$ to $1.0 \mathrm{E}+9 \mathrm{n} / \mathrm{cm}^{2} \mathrm{~s}$.

(2) Shippingport Neutron Shield Tank (NST) data [4], with irradiation temperature $\sim 54^{\circ} \mathrm{C}$, with fast flux $\sim 2.0 \mathrm{E}+09 \mathrm{n} / \mathrm{cm}^{2} \mathrm{~s}$. This is about twice higher fast neutron flux than HFIR's surveillance data.

(3) Steele and Hawthorne low temperature data [5] with irradiation temperature less than $93^{\circ} \mathrm{C}$. Most data are irradiated in ORNL low intensity test reactor (LITR), which has a fast flux range of 2-3.0E+12 n/cm ${ }^{2} \mathrm{~s}$, and in Brookhaven graphite reactor with fast flux of $5.0 \mathrm{E}+11$ $\mathrm{n} / \mathrm{cm}^{2} \mathrm{~s}$.

(4) Test reactor data from ASTM publication [6] related to A212B correlation monitor materials $(\mathrm{CMM})$, with irradiation temperature less than $150^{\circ} \mathrm{C}$, and most with fast flux less than 3.0 $\mathrm{E}+12 \mathrm{n} / \mathrm{cm}^{2} \mathrm{~s}$. As for fast fluence $>1.0 \mathrm{E}+20 \mathrm{n} / \mathrm{cm}^{2}$, the National Reactor Test Station material test reactor (MTR) with fast flux of $1.0 \mathrm{E}+13 \mathrm{n} / \mathrm{cm}^{2} \mathrm{~s}$ was used as the irradiation facility.

Accurate temperature measurement in reactor experiments is required for a consistent and accurate radiation effect study. In some cases, eutectic alloys and pure metals were used for monitoring temperature profiles within the irradiated capsule assembly. However, this has not always been possible from the earlier irradiation experiments, due to the limited and complex facilities for introduction of instrument lines to the interior of a commercial light-water nuclear 
reactor. An additional factor has been that radiation effects would be measurably affected by variations of exposure temperature, even those less than $10^{\circ} \mathrm{C}$. Furthermore, for an aging passive capsule assembly, the thermal conductivity for the capsule wall and irradiated specimens could be degraded during the service due to radiation induced microstructure change, in addition to the capsule wall oxide build-up. Thus, due to accumulated damage process, the irradiation temperature experienced by the irradiated specimens with relatively higher dose (or the long term data) could be higher than that of a relatively lower dose data with similar capsule design configurations.

The details of the data and the associated references for developing Fig.1's trend curve are provided in the spreadsheet HFIR-trend cure_1.xlsx, and shown in Tables 1-3. A scaling factor of $1.392 \mathrm{E}-21 \mathrm{~cm}^{2}$ [1] was used to convert test reactors' fast fluence data to dpa. The International Mathematics and Statistics Library's (IMSL) optimization routine (GNSS) was used for developing the trend curve and the associated $2-\sigma$ uncertainty bounds.

\subsection{Trend Curve Includes High Dose Data}

It is noted here that the high dose data, dpa $>0.1$, shown in Fig. 1, were not included in the earlier HFIR trend curve development reported in Ref. 1. The governing equation of the embrittlement trend curve, with all the data shown in Fig. 1, is written as below.

$\Delta \operatorname{NDTT}\left({ }^{\circ} \mathrm{C}\right)=23.1 \log (x)^{2}+189.9 \log (x)+394.9$, with 2- $\sigma$ uncertainty of $35.4^{\circ} \mathrm{C}$ where, parameter " $x$ " is "total dpa."

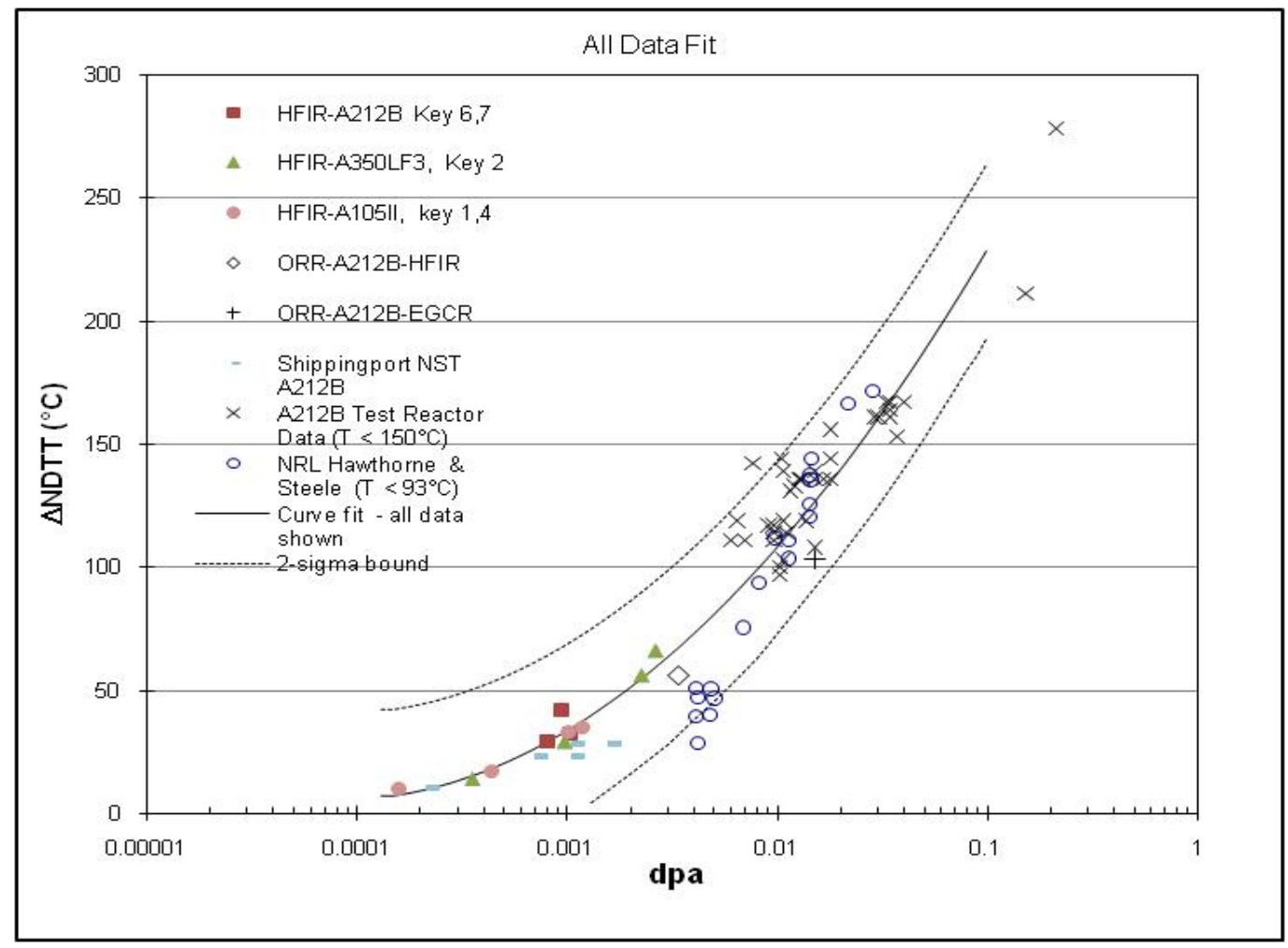

Figure 1 HFIR RPV steel trend curve fit from ref. [1], including dpa >0.1 data. 


\section{Table 1 HFIR Surveillance Program Related Data as of 1994}

$\begin{array}{lrlllrl}\text { PLANT_ID } & \text { EFPY } & \text { Cap_F1 } & \text { DPA } & \text { DPA_T } & \text { DTTX } & \text { MAT } \\ \text { HFIR } & 15.01 & 8.30 \mathrm{E}+16 & 1.32 \mathrm{E}-04 & 8.11 \mathrm{E}-04 & 29 & \text { A212B } \\ \text { HFIR } & 17.53 & 9.70 \mathrm{E}+16 & 1.53 \mathrm{E}-04 & 9.47 \mathrm{E}-04 & 42 & \text { A212B } \\ \text { HFIR } & 19.20 & 1.06 \mathrm{E}+17 & 1.68 \mathrm{E}-04 & 1.04 \mathrm{E}-03 & 32 & \text { A212B } \\ \text { HFIR } & 2.34 & 1.05 \mathrm{E}+17 & 1.64 \mathrm{E}-04 & 3.53 \mathrm{E}-04 & 14 & \text { A350LF3 } \\ \text { HFIR } & 6.45 & 2.89 \mathrm{E}+17 & 4.52 \mathrm{E}-04 & 9.72 \mathrm{E}-04 & 29 & \text { A350LF3 } \\ \text { HFIR } & 15.01 & 6.74 \mathrm{E}+17 & 1.05 \mathrm{E}-03 & 2.26 \mathrm{E}-03 & 56 & \text { A350LF3 } \\ \text { HFIR } & 17.53 & 7.87 \mathrm{E}+17 & 1.23 \mathrm{E}-03 & 2.64 \mathrm{E}-03 & 66 & \text { A350LF3 } \\ \text { HFIR } & 2.34 & 3.12 \mathrm{E}+16 & 6.63 \mathrm{E}-05 & 1.59 \mathrm{E}-04 & 10 & \text { A105II } \\ \text { HFIR } & 6.45 & 8.60 \mathrm{E}+16 & 1.83 \mathrm{E}-04 & 4.38 \mathrm{E}-04 & 17 & \text { A105II } \\ \text { HFIR } & 15.01 & 2.00 \mathrm{E}+17 & 4.25 \mathrm{E}-04 & 1.02 \mathrm{E}-03 & 33 & \text { A105II } \\ \text { HFIR } & 17.53 & 2.34 \mathrm{E}+17 & 4.97 \mathrm{E}-04 & 1.19 \mathrm{E}-03 & 35 & \text { A105II } \\ \text { ORR } & & 2.43 \mathrm{E}+18 & 3.39 \mathrm{E}-03 & 3.39 \mathrm{E}-03 & 56 & \text { A212B HFIR } \\ \text { ORR } & & 9.80 \mathrm{E}+18 & 1.52 \mathrm{E}-02 & 1.52 \mathrm{E}-02 & 103 & \text { A212B EGCR } \\ \text { ORR } & & 1.54 \mathrm{E}+17 & 2.14 \mathrm{E}-04 & 2.14 \mathrm{E}-04 & 10 & \text { A212B EGCR } \\ \text { SP } & & 2.67 \mathrm{E}+17 & 7.10 \mathrm{E}-04 & 7.10 \mathrm{E}-04 & 23 & \text { A212B } \\ \text { SP } & & 4.00 \mathrm{E}+17 & 1.07 \mathrm{E}-03 & 1.07 \mathrm{E}-03 & 23 & \text { A212B } \\ \text { SP } & & 4.00 \mathrm{E}+17 & 1.07 \mathrm{E}-03 & 1.07 \mathrm{E}-03 & 28 & \text { A212B } \\ \text { SP } & & 6.00 \mathrm{E}+17 & 1.60 \mathrm{E}-03 & 1.60 \mathrm{E}-03 & 28 & \text { A212B }\end{array}$

Cap-F1 - Fast fleunce (energy $>1 \mathrm{MeV}$ ), unit in $\mathrm{n} / \mathrm{cm}^{2}$

DPA_T - Total dpa

DTTX - NDTT shift in ${ }^{\circ} \mathrm{C}$

HFIR and ORR data are from: Remec, I., Wang, J. A., Kam, F. B. K., and Farrell, K., "Effects of Gamma-Induced Displacements on HFIR Pressure Vessel Materials," Journal of Nuclear Materials, Volume_217 pp. 258-268, 1994.

Shippingport data are from Reference 4, "NUREG/CR-5748, pages 4, 25, "Radiation Embrittlement of the Neutron Shield Tank from the Shippingport Reactor." 
Table 2 Low Temperature Data (Temp. $<93^{\circ} \mathrm{C}$ ) from Steele and Hawthorne [5]

$\begin{array}{rrlrrll}\text { CSP_F1_log } & \text { FLUENC } & \text { DPA } & \text { DTT30_F } & \text { DTTX } & \text { MAT } & \text { REF } \\ 19.30988 & 2.041 \mathrm{E}+19 & 2.837 \mathrm{E}-02 & 308 . & 171.1 & \text { A201 Steel } & \text { NRL 5629 } \\ 19.19459 & 1.565 \mathrm{E}+19 & 2.176 \mathrm{E}-02 & 299 . & 166.3 & \text { A212B } & \text { NRL 5629 } \\ 19.02224 & 1.053 \mathrm{E}+19 & 1.463 \mathrm{E}-02 & 259 . & 143.6 & \text { Weld B } & \text { NRL } 5629 \\ 19.01421 & 1.033 \mathrm{E}+19 & 1.436 \mathrm{E}-02 & 247 . & 137.2 & \text { SA336 } & \text { NRL 5629 } \\ 19.01648 & 1.039 \mathrm{E}+19 & 1.444 \mathrm{E}-02 & 243 . & 135.2 & \text { A302B } & \text { NRL 5629 } \\ 19.00976 & 1.023 \mathrm{E}+19 & 1.422 \mathrm{E}-02 & 226 . & 125.3 & \text { Weld A } & \text { NRL 5629 } \\ 19.01117 & 1.026 \mathrm{E}+19 & 1.426 \mathrm{E}-02 & 217 . & 120.4 & \text { A212B } & \text { NRL 5629 } \\ 18.84705 & 7.032 \mathrm{E}+18 & 9.770 \mathrm{E}-03 & 201 . & 111.7 & \text { A302B } & \text { NRL 5629 } \\ 18.91214 & 8.168 \mathrm{E}+18 & 1.135 \mathrm{E}-02 & 200 . & 110.9 & \text { A201 Steel } & \text { NRL 5629 } \\ 18.91373 & 8.198 \mathrm{E}+18 & 1.140 \mathrm{E}-02 & 186 . & 103.4 & \text { A212B } & \text { NRL 5629 } \\ 18.77230 & 5.920 \mathrm{E}+18 & 8.230 \mathrm{E}-03 & 168 . & 93.4 & \text { A201 Steel } & \text { NRL 5629 } \\ 18.69509 & 4.956 \mathrm{E}+18 & 6.890 \mathrm{E}-03 & 136 . & 75.3 & \text { Weld A } & \text { NRL 5629 } \\ 18.54305 & 3.492 \mathrm{E}+18 & 4.850 \mathrm{E}-03 & 91 . & 50.6 & \text { A201 Steel } & \text { NRL 5629 } \\ 18.47301 & 2.972 \mathrm{E}+18 & 4.130 \mathrm{E}-03 & 92 . & 50.9 & \text { A212B } & \text { NRL 5629 } \\ 18.55818 & 3.616 \mathrm{E}+18 & 5.030 \mathrm{E}-03 & 84 . & 46.7 & \text { Weld B } & \text { NRL 5629 } \\ 18.48179 & 3.032 \mathrm{E}+18 & 4.220 \mathrm{E}-03 & 84 . & 46.9 & \text { Weld A } & \text { NRL 5629 } \\ 18.53745 & 3.447 \mathrm{E}+18 & 4.790 \mathrm{E}-03 & 72 . & 39.9 & \text { A201 Steel } & \text { NRL 5629 } \\ 18.47278 & 2.970 \mathrm{E}+18 & 4.130 \mathrm{E}-03 & 71 . & 39.4 & \text { SA336 } & \text { NRL 5629 } \\ 18.48203 & 3.034 \mathrm{E}+18 & 4.220 \mathrm{E}-03 & 52 . & 28.7 & \text { A302B } & \text { NRL 5629 }\end{array}$

where, CSP_F1_log - log scale fast fluence, DTT30_F - NDTT shift at $30 \mathrm{ft}-1 \mathrm{~b}$ level in ${ }^{\circ} \mathrm{F}$.

NRL-5629: L.E. Steele and J. R. Hawthorne, US Naval Research Laboratory Report, 1961 
Table 3 A212B CMM Test Reactor Data (Temp. < $150^{\circ} \mathrm{C}$ ) [6]

\begin{tabular}{|c|c|c|c|c|c|}
\hline CSP_F1 & DPA & DPA_T & DTTX & MAT & REF \\
\hline $7.60 \mathrm{E}+18$ & 1.06E-02 & 1.06E-02 & 144 & A212B & ASTM DS54 \\
\hline $5.50 \mathrm{E}+18$ & 7.70E-03 & 7.70E-03 & 142 & $A 212 B$ & ASTM DS54 \\
\hline $7.80 \mathrm{E}+18$ & 1.08E-02 & 1.08E-02 & 139 & $A 212 B$ & ASTM DS54 \\
\hline $4.40 \mathrm{E}+18$ & $6.10 \mathrm{E}-03$ & $6.10 \mathrm{E}-03$ & 111 & $A 212 B$ & ASTM DS54 \\
\hline $4.70 \mathrm{E}+18$ & $6.50 \mathrm{E}-03$ & $6.50 \mathrm{E}-03$ & 119 & $A 212 B$ & ASTM DS54 \\
\hline $5.10 \mathrm{E}+18$ & 7.10E-03 & 7.10E-03 & 111 & $A 212 B$ & ASTM DS54 \\
\hline $8.40 \mathrm{E}+18$ & 1.17E-02 & 1.17E-02 & 131 & $A 212 B$ & ASTM DS54 \\
\hline $8.80 \mathrm{E}+18$ & $1.22 \mathrm{E}-02$ & 1.22E-02 & 133 & $A 212 B$ & ASTM DS54 \\
\hline $9.20 \mathrm{E}+18$ & $1.28 \mathrm{E}-02$ & $1.28 \mathrm{E}-02$ & 136 & $A 212 B$ & ASTM DS54 \\
\hline $2.40 \mathrm{E}+19$ & 3.34E-02 & 3.34E-02 & 167 & $A 212 B$ & ASTM DS54 \\
\hline $2.50 \mathrm{E}+19$ & $3.48 \mathrm{E}-02$ & $3.48 \mathrm{E}-02$ & 167 & $A 212 B$ & ASTM DS54 \\
\hline $2.50 \mathrm{E}+19$ & $3.48 \mathrm{E}-02$ & $3.48 \mathrm{E}-02$ & 167 & $A 212 B$ & ASTM DS54 \\
\hline $7.80 \mathrm{E}+18$ & $1.08 \mathrm{E}-02$ & $1.08 \mathrm{E}-02$ & 103 & $A 212 B$ & ASTM DS54 \\
\hline $6.60 \mathrm{E}+18$ & $9.20 \mathrm{E}-03$ & $9.20 \mathrm{E}-03$ & 117 & A212B & ASTM DS54 \\
\hline $2.50 \mathrm{E}+19$ & $3.48 \mathrm{E}-02$ & $3.48 \mathrm{E}-02$ & 164 & $A 212 B$ & ASTM DS54 \\
\hline $2.10 \mathrm{E}+19$ & 2.92E-02 & 2.92E-02 & 161 & $A 212 B$ & ASTM DS54 \\
\hline $2.70 \mathrm{E}+19$ & 3.75E-02 & 3.75E-02 & 153 & $A 212 B$ & ASTM DS54 \\
\hline $2.90 \mathrm{E}+19$ & 4.03E-02 & 4.03E-02 & 167 & A212B & ASTM DS54 \\
\hline $1.30 \mathrm{E}+19$ & $1.81 \mathrm{E}-02$ & 1.81E-02 & 136 & $A 212 B$ & ASTM DS54 \\
\hline $1.10 \mathrm{E}+19$ & 1.53E-02 & 1.53E-02 & 108 & A212B & ASTM DS54 \\
\hline $1.10 \mathrm{E}+19$ & 1.53E-02 & 1.53E-02 & 108 & $A 212 B$ & ASTM DS54 \\
\hline $7.00 \mathrm{E}+18$ & $9.70 \mathrm{E}-03$ & $9.70 \mathrm{E}-03$ & 111 & $A 212 B$ & ASTM DS54 \\
\hline $7.00 \mathrm{E}+18$ & $9.70 \mathrm{E}-03$ & $9.70 \mathrm{E}-03$ & 117 & A212B & ASTM DS54 \\
\hline $7.00 \mathrm{E}+18$ & $9.70 \mathrm{E}-03$ & $9.70 \mathrm{E}-03$ & 114 & $A 212 B$ & ASTM DS54 \\
\hline $7.80 \mathrm{E}+18$ & $1.08 \mathrm{E}-02$ & $1.08 \mathrm{E}-02$ & 119 & $A 212 B$ & ASTM DS54 \\
\hline $1.10 \mathrm{E}+19$ & 1.53E-02 & 1.53E-02 & 136 & $A 212 B$ & ASTM DS54 \\
\hline $1.30 \mathrm{E}+19$ & 1.81E-02 & 1.81E-02 & 156 & $A 212 B$ & ASTM DS54 \\
\hline $1.20 \mathrm{E}+19$ & 1.67E-02 & 1.67E-02 & 136 & A212B & ASTM DS54 \\
\hline $2.50 \mathrm{E}+19$ & $3.48 \mathrm{E}-02$ & $3.48 \mathrm{E}-02$ & 161 & $A 212 B$ & ASTM DS54 \\
\hline $1.00 \mathrm{E}+19$ & 1.39E-02 & 1.39E-02 & 119 & $A 212 B$ & ASTM DS54 \\
\hline $7.50 \mathrm{E}+18$ & $1.04 \mathrm{E}-02$ & 1.04E-02 & 100 & $A 212 B$ & ASTM DS54 \\
\hline $8.00 \mathrm{E}+18$ & 1.11E-02 & 1.11E-02 & 114 & A212B & ASTM DS54 \\
\hline $1.10 \mathrm{E}+19$ & 1.53E-02 & 1.53E-02 & 139 & A212B & ASTM DS54 \\
\hline $1.30 \mathrm{E}+19$ & $1.81 \mathrm{E}-02$ & 1.81E-02 & 144 & $A 212 B$ & ASTM DS54 \\
\hline $2.20 \mathrm{E}+19$ & 3.06E-02 & 3.06E-02 & 161 & $A 212 B$ & ASTM DS54 \\
\hline $1.53 \mathrm{E}+20$ & 2.13E-01 & 2.13E-01 & 278 & A212B & ASTM DS54 \\
\hline $1.10 \mathrm{E}+20$ & 1.53E-01 & 1.53E-01 & 211 & A212B & ASTM DS54 \\
\hline $7.50 \mathrm{E}+18$ & 1.04E-02 & 1.04E-02 & 97 & $A 212 B$ & ASTM DS54 \\
\hline $9.50 \mathrm{E}+18$ & 1.32E-02 & 1.32E-02 & 136 & $A 212 B$ & ASTM DS54 \\
\hline
\end{tabular}

J. R. Hawthorne, ASTM DS54: Radiation Effects Information Generated on the ASTM Reference Correlation-Monitor Steels, 1974. 


\subsection{Low Temperature RPV Embrittlement Predictive Curve w/o High Dose Data}

In order to match the data used in the 1994 HFIR trend curve development, a separate low temperature RPV steel embrittlement trend curve was developed, where data with dpa $>0.1$ were excluded from the fitting, shown in Fig.2. This generated the same curve as that developed in Ref. 1.

The governing equation of this curve is written as below.

$\Delta \operatorname{NDTT}\left({ }^{\circ} \mathrm{C}\right)=31.3 \log (x)^{2}+233.5 \log (x)+448.7$, with $2-\sigma$ uncertainty of $33.4^{\circ} \mathrm{C}$

where, parameter " $x$ " is referred to "total dpa."

The comparison of the above two trend curves is illustrated in Fig. 3. It is clear that the high dose data have significant impact to the embrittlement predictions at higher dose range due to their low $\triangle$ NDTT values. It is also noted that Hawthorne's data at relatively lower dose range fall below the mean curves in both predictions. Therefore, this warrants a detailed investigation on the Hawthorne data. It was found out that only 4 of Hawthorne's data are referred to A212B steel, and the data at the lower dose are mostly from low copper weld and A302B material, instead of A212B steel.

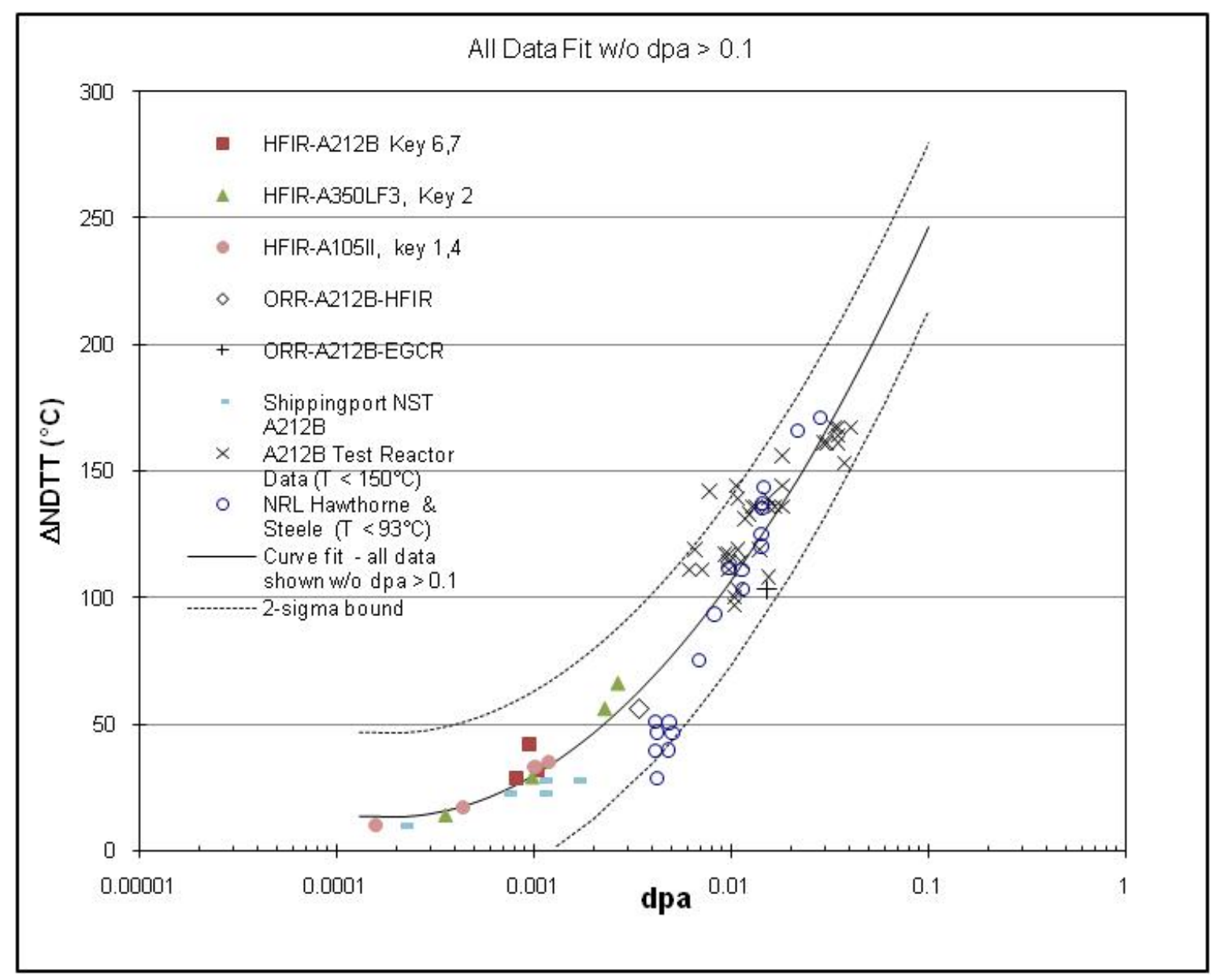


Figure 2 Low temperature RPV steel irradiation embrittlement trend curve fit, including dpa $>0.1$ data.

\subsection{Comparison of Low Temperature RPV Embrittlement Trend Curves w/ and w/o High Dose Data}

In the dose range compatible to that of the projected HFIR RPV life extension, say around 0.01 dpa range, both of the trend curves give very similar predictions. However, due to the lack of intermediate dose data that cover the range between these high dose data and the nearest lower dose range, from the statistical point of view, these high dose data have a significant impact on the curve fitting, especially at the higher dose range. Moreover, due to large uncertainty inherited from these high dose data (which were irradiated in an MTR facility), such as dose-rate and irradiation temperature effects, the embrittlement data of dpa $>0.1$ were excluded from the low temperature RPV embrittlement predictive curve development.

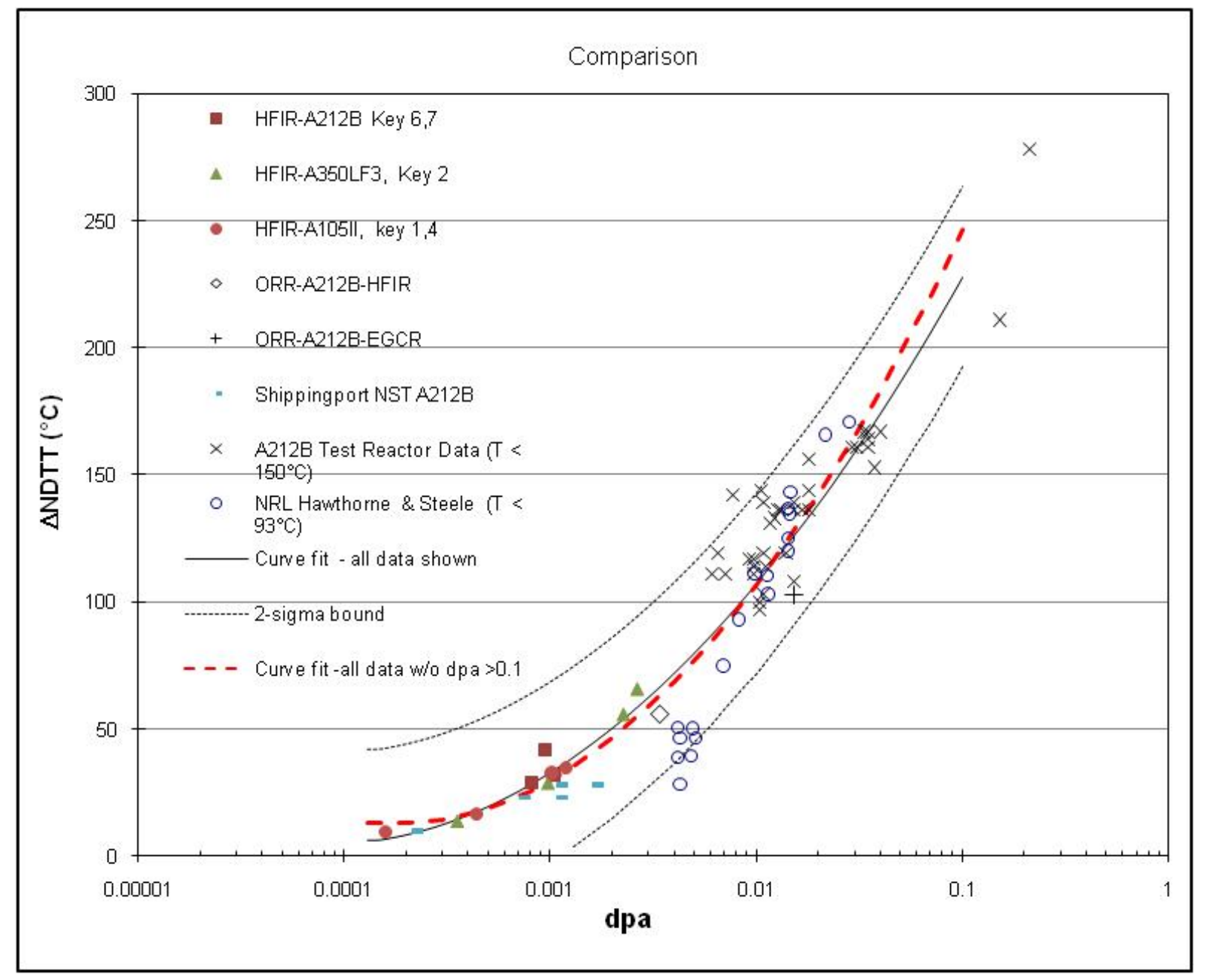

Figure 3 Comparison of the low temperature irradiation embrittlement trend curves developed with and without the high dose data, dpa $>0.1$. 


\subsection{Hawthorne Low Temperature Data}

Because only 4 data points from Hawthorne's low temperature data [5] are from A212B materials, a low temperature trend curve was developed which excludes the data with dpa $>0.1$ and only retains the A212B data from Hawthorne's low temperature data, shown in Fig. 4. The governing equation of this embrittlement trend curve is written as below.

$\Delta \operatorname{NDTT}\left({ }^{\circ} \mathrm{C}\right)=22.4 \log (x)^{2}+186.6 \log (x)+394.8$, with $2-\sigma$ uncertainty of $28.8^{\circ} \mathrm{C}$ where, parameter " $x$ " is "total dpa."



Figure 4 Trend curves developed w/o dpa $>0.1$ and only retained A212B data from Hawthorne's data. 


\subsection{Comparison of Trend Curves w/ All or w/ only A212B Data from Hawthorne's Data}

A comparison of the above two trend curves, with all the NDTT shift data or with only A212B data from Hawthorne low temperature data, was carried out and illustrated in Fig. 5. It clearly indicates that the low temperature embrittlement data from Hawthorne's non-A212B data has significant impact on the embrittlement trend throughout the entire dose range. And the trend curve without non-A212B Hawthorne data appears to fit the HFIR surveillance data better than the trend curve developed based on all Hawthorne's low temperature data. Thus, it was decided to retain only the Hawthorne A212B data for the trend curve development. This reduced data set was also used in the Task 3 study, which covers the consideration of data adjustment for the A212B CMM test reactor data that have higher irradiation temperature compared to that of HFIR surveillance data.

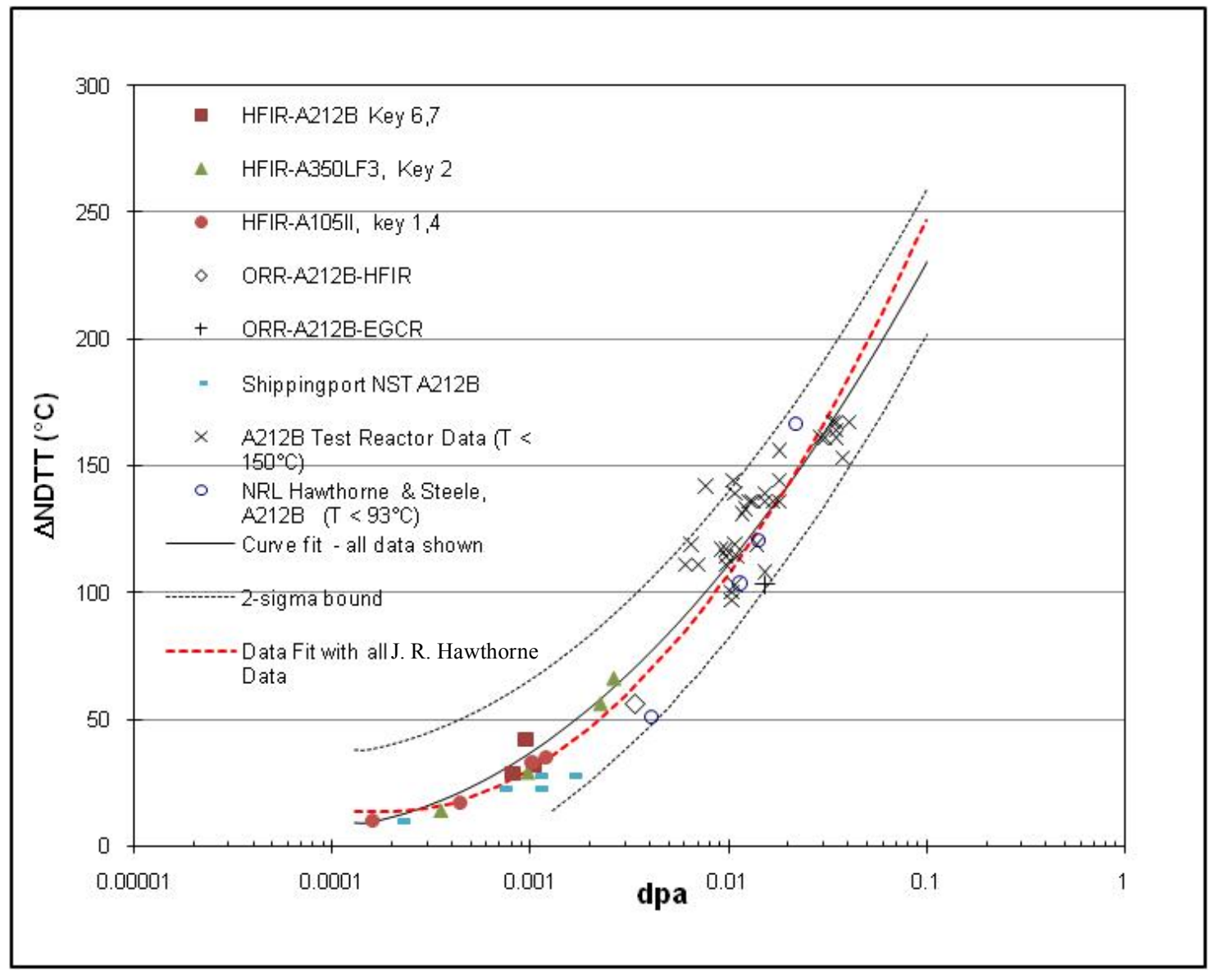

Figure 5 Comparison of low temperature RPV embrittlement trend curves developed with all data or with only A212B data from Hawthorne low temperature database. 


\section{TASK 2: Additional New Embrittlement Data Associated with A212B Steels}

The objective of this task is to collect:

Additional test reactor data associated with A212B material that are not covered by the database used for the 1994 HFIR RPV Steel Accelerated Embrittlement Study.

\subsection{New NDTT Shift Data for A212B Steel}

Seventeen Charpy NDTT shift data of A212B materials with irradiation temperature less than $93^{\circ} \mathrm{C}\left(200^{\circ} \mathrm{F}\right)$ were collected from L. F. Porter's paper, "Radiation effects in steels," published in ASTM STP No. 276, 1959 [7-11]. The details of these data are provided in the spreadsheet, Modification_cals.xlsx, and illustrated in Tables 4-6.

Ten out of the 17 data points are from sub-size Charpy specimens with 0.2 -inch square crosssection. These sub-size data have much less embrittlement rate compared to that of test reactor data from $\mathrm{A} 212 \mathrm{~B} \mathrm{CMM}$ materials with irradiation temperature $\sim 150^{\circ} \mathrm{C}$. Thus, a more detailed investigation was carried out on the data sources of these 17 data points. Moreover, a new set of $\mathrm{A} 212 \mathrm{~B} \mathrm{CMM}$ test reactor data with a mean irradiation temperature of $475^{\circ} \mathrm{F}$ was also generated (as illustrated in Table 7), for the purpose of calibrating/evaluating an adjusted shift value for the consideration of irradiation temperature effect.

The 17 new data points originated from 4 different sources [8-11], and the associated irradiation temperatures for the sub-size Charpy data are $200^{\circ} \mathrm{F}$ and $175^{\circ} \mathrm{F}$. The A212B CMM test reactor data including a new $\mathrm{A} 212 \mathrm{~B}$ data set with $475^{\circ} \mathrm{F}$ irradiation temperature, and Hawthorne's low temperature data, are illustrated in Fig. 6, where the 17 new data points were further grouped into sub-size and standard Charpy data sets.

In Fig. 6, a significantly lower embrittlement trend was observed from 17 new data points (in solid symbols) compared to that of A212B CMM data. It's noted here that these 17 data points were irradiated at lower irradiation temperature than that of A212B CMM data. The flux ranges of these 17 data are similar to that of the A212B CMM data, except for the very high dose data, which were irradiated in an MTR facility near Arco, Idaho. (It is noted here that the neutron flux in the MTR is about 10 times that in the ORNL LITR facility)

Based on the above, the potential root cause of low embrittlement phenomenon of these new data could be attributed to specimen size effect, and the potential of error in controlling the capsule temperature and estimating the specimen irradiation temperature. A more detailed discussion on the subject related to specimen size effect is provided in Chapter 6 - Small Specimen Technology in Applying to Reactor RPV Surveillance.

\subsection{The Detailed Investigation of the New Embrittlement Data}

Further effort was carried out to investigate the raw Charpy impact test data from the available data sources provided in references 7-10. It was found out, in many cases, that the baseline A212B steels used for preparing these test samples were further heat treated for tailoring material 
investigation. For example, for two high-dose data, the Charpy impact test samples were normalized from $1900^{\circ} \mathrm{F}$ before carrying out the irradiation experiments. And in other cases, higher normalization temperatures or hot rolling processes were applied to the baseline of the A212B materials before manufacturing the specimens. These heat-treatments or/and additional material modification processes applied to the raw A212B materials, or to the test specimens, could be the root cause of these 17 points showing much less radiation embrittlement.

Moreover, due to sub-size samples used for the investigation, these reported NDTT data were calibrated with a transition temperature indexed at 50\% upper shelf impact energy level for the baseline and the irradiated data, respectively, shown in reference *40 listed in Table 4 . Such an approach w/o a definite index-energy level, (for example, $30 \mathrm{ft}-\mathrm{lb}$ used for standard Charpy test data), has generated significant inconsistency for sub-size data while comparing baseline and irradiated Charpy data. This added additional bias to the NDTT shift evaluations, especially for the high dose data. Furthermore, only Charpy fitting curves, no tabulated data, are presented in the reports for these 17 data points; and only a few of these Charpy fitting curves showed the individual Charpy data. Based on the four available raw Charpy test data with high dose, rough Charpy curve fittings were performed. The index for measuring NDTT shift was set to $50 \%$ upper shelf energy from the irradiated Charpy fitting curve for both the baseline and irradiated Charpy impact data. This has resulted in increases in these NDTT shifts. For example, for a $200^{\circ} \mathrm{F}$ irradiation temperature, in Table 6, NDTT shifts were increased by $16 \%$ and $29 \%$, for fast neutron fluence of $3.0 \mathrm{E}+19 \mathrm{n} / \mathrm{cm}^{2}$ and $1.8 \mathrm{E}+20 \mathrm{n} / \mathrm{cm}^{2}$, respectively. The A212B test reactor data and 17 data points with the adjusted NDTT shift data are shown in Fig. 7; the adjusted data are included in Table 6, marked with highlighting.

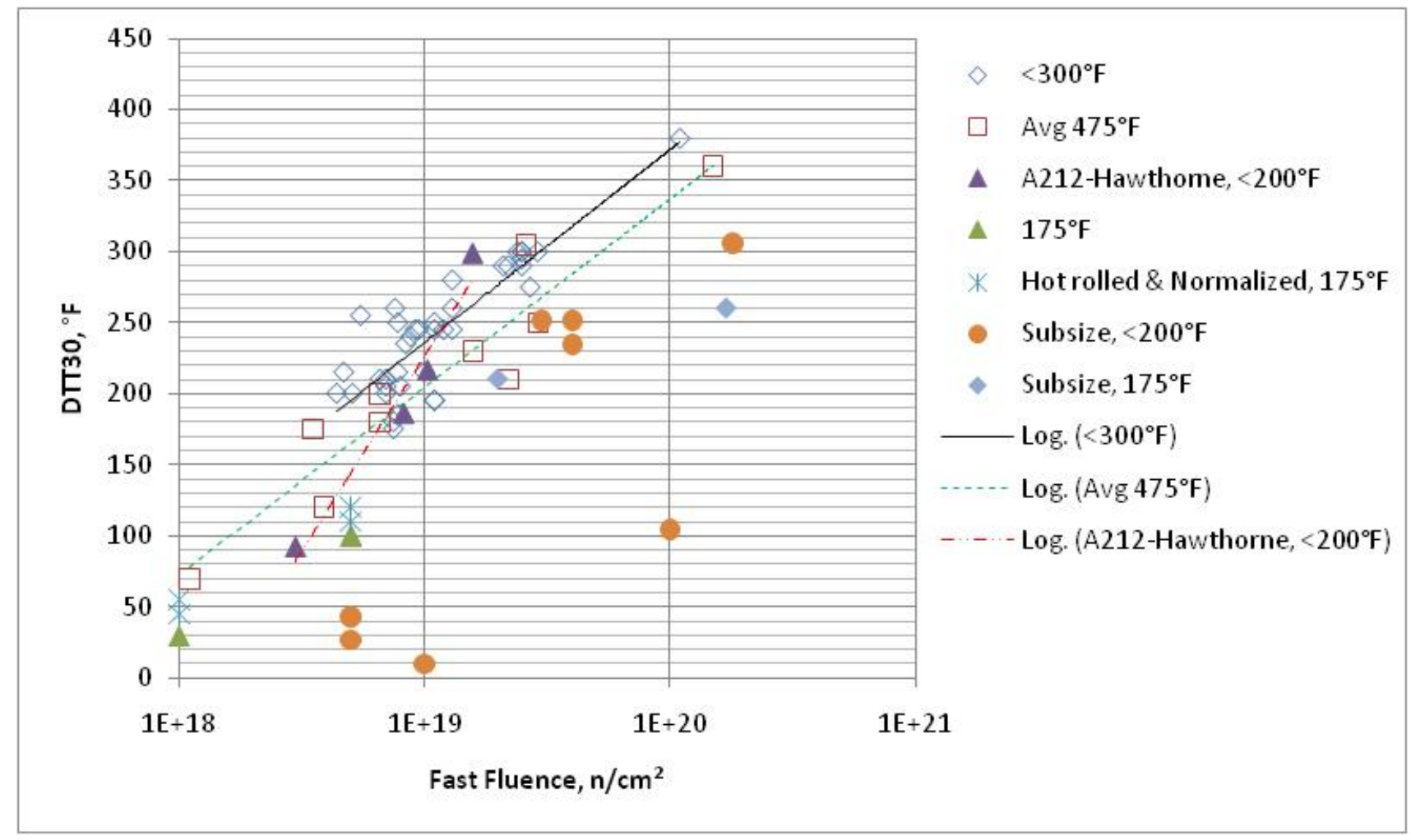


Figure 6 Test reactor data from A212B CMM data, Hawthorne A212B data, and Porter A212B data. All are standard Charpy samples, except noted in the figure legend.

Table 4 Additional Embrittlement Data for A212B Steels

$\begin{array}{ccrrlr}\text { Irr_Temp, }{ }^{\circ} \mathrm{F} & \text { FLUENC } & \text { DTT30/F } & \text { DTT30_C } & \text { MAT } & \text { Detailed Ref } \\ <200 & 1.00 \mathrm{E}+19 & 10 & 6 & \text { A212B } & 5 \\ <200 & 1.00 \mathrm{E}+20 & 105 & 58 & \text { A212B } & 5 \\ <200 & 5.00 \mathrm{E}+18 & 27 & 15 & \text { A212B } & 14 \\ <200 & 4.00 \mathrm{E}+19 & 235 & 131 & \text { A212B } & 14 \\ <200 & 5.00 \mathrm{E}+18 & 43 & 24 & \text { A212B } & 14 \\ <200 & 4.00 \mathrm{E}+19 & 252 & 140 & \text { A212B } & 14 \\ <200 & 3.00 \mathrm{E}+19 & 252 & 140 & \text { A212B } & 40 \\ <200 & 1.80 \mathrm{E}+20 & 306 & 170 & \text { A212B } & 40 \\ 175 & 2.00 \mathrm{E}+19 & 210 & 117 & \text { A212B } & 27 \\ 175 & 1.70 \mathrm{E}+20 & 260 & 144 & \text { A212B } & 27 \\ 175 & 1.00 \mathrm{E}+18 & 30 & 17 & \text { A212B } & 27 \\ 175 & 5.00 \mathrm{E}+18 & 100 & 56 & \text { A212B } & 27 \\ 175 & 1.00 \mathrm{E}+18 & 55 & 31 & \text { A212B } & 27 \\ 175 & 5.00 \mathrm{E}+18 & 110 & 61 & \text { A212B } & 27 \\ 175 & 1.00 \mathrm{E}+18 & 45 & 25 & \text { A212B } & 27 \\ 175 & 5.00 \mathrm{E}+18 & 120 & 67 & \text { A212B } & 27 \\ 175 & 5.00 \mathrm{E}+18 & 100 & 56 & \text { A212B } & 27\end{array}$

Additional embrittlement data are from L. F. Porter, "Radiation Effects in Steel," pp. 147-195, ASTM STP No. 276, 1959.

*5 - J. C. Wilson and R. G. Berggren, "Effects of Neutron Irradiation in Steels," Proceedings, ASTM, Vol. 55, p689, 1955.

*14 - R. G. Berggren and J. C. Wilson, "Recent Data on the Effects of Neutron Irradiation on Structural Metals and Alloys," ORNL-CF-56-11-1, January 1957.

*27 - J. C. Wilson, R. G. Berggren, F. M. Grizzel, and J. T. Humphries, "HRP Radiation Metallurgy, Notch Impact Properties," ORNL-2614, August 1958.

*40 - M. L. Bleiberg, Effect of Neutron Bombardment Upon the Properties of ASTM Type SA212B Steel," WAPD-T-206, October 1955.

Table 5 Standard Charpy Data from Porter's Data for A212B Steels

\begin{tabular}{|c|c|c|c|c|c|c|}
\hline \multicolumn{7}{|l|}{ Standard } \\
\hline Charpy & Cap_temp & FLUENC & DTT30/F & MAT & REF & $\begin{array}{l}\text { Notes } \\
\text { item } 43,5 / 8 \text {-in plate, normalized from }\end{array}$ \\
\hline (low USE) & 175 & $1.00 \mathrm{E}+18$ & 30 & A212B & 27 & $\begin{array}{l}1700^{\circ} \mathrm{F} \\
\text { item } 43,5 / 8 \text {-in plate, normalized from }\end{array}$ \\
\hline (low USE) & 175 & $5.00 \mathrm{E}+18$ & 100 & A212B & 27 & $\begin{array}{l}1700^{\circ} \mathrm{F} \\
\text { item } 43,5 / 8 \text {-in plate, normalized from }\end{array}$ \\
\hline (low USE) & 175 & $5.00 \mathrm{E}+18$ & 100 & A212B & 27 & $1700^{\circ} \mathrm{F}$ \\
\hline hot rolled & 175 & $1.00 \mathrm{E}+18$ & 55 & A212B & 27 & \\
\hline hot rolled & 175 & $5.00 \mathrm{E}+18$ & 110 & A212B & 27 & \\
\hline
\end{tabular}




$\begin{array}{lrrrrrr}\text { normalized } & 175 & 1.00 \mathrm{E}+18 & 45 & \text { A212B } & 27 & \\ \text { normalized } & 175 & 5.00 \mathrm{E}+18 & 120 & \text { A212B } & 27 & \text { 6-in plate, High USE }\end{array}$

Table 6 Sub-size Charpy Data from Porter's Data for A212B Steels

\begin{tabular}{|c|c|c|c|c|c|}
\hline $\begin{array}{l}\operatorname{Irr}{ }_{-}{ }^{\circ}{ }^{\circ} \mathrm{F} \\
<200\end{array}$ & $\begin{array}{l}\text { FLUENC } \\
1.00 \mathrm{E}+19\end{array}$ & $\begin{array}{l}\text { DTT } 30 /{ }^{\circ} \mathrm{F} \\
10\end{array}$ & Adjusted & $\begin{array}{l}\text { Ref } \\
5\end{array}$ & $\begin{array}{l}\text { Notes } \\
\text { Specimen are normalized from 1900F before irradiation }\end{array}$ \\
\hline$<200$ & $1.00 \mathrm{E}+20$ & 105 & & 5 & Specimen are normalized from 1900F before irradiation \\
\hline$<200$ & $5.00 \mathrm{E}+18$ & 27 & & 14 & $\begin{array}{l}\text { A212 base then manufactured to } \mathrm{A} 300 \text { (aluminum-killed, fine } \\
\text { grained low-temperature practice. }\end{array}$ \\
\hline$<200$ & $4.00 \mathrm{E}+19$ & 235 & & 14 & $\begin{array}{l}\text { A212 base then manufactured to A300 (aluminum-killed, fine } \\
\text { grained low-temperature practice. }\end{array}$ \\
\hline$<200$ & $5.00 \mathrm{E}+18$ & 43 & & 14 & Hot rolled \\
\hline$<200$ & $4.00 \mathrm{E}+19$ & 252 & & 14 & Hot Rolled \\
\hline$<200$ & 3.00E+19 & 252 & 293 & 40 & $\begin{array}{l}\text { Correct from raw data, C=0.29 wt } \%, \mathrm{Cu}<0.05 \text { wt } \%, \mathrm{P}=0.020 \\
\text { wt\%; small capsule design }\end{array}$ \\
\hline$<200$ & $1.80 \mathrm{E}+20$ & 306 & 390 & 40 & $\begin{array}{l}\text { Correct from raw data, C=0.29 wt } \%, \mathrm{Cu}<0.05 \text { wt\%, P=0.020 } \\
\text { wt\%; small capsule design }\end{array}$ \\
\hline 175 & $2.00 \mathrm{E}+19$ & 210 & 247 & 27 & in MTR, large capsule design, no raw data, correct from curve \\
\hline 175 & $1.70 \mathrm{E}+20$ & 260 & 312 & 27 & in MTR, large capsule design, no raw data, correct from curve \\
\hline
\end{tabular}

Table 7 A212B CMM Test Reactor Data with Mean Temperature of $475^{\circ} \mathrm{F}$

$\begin{array}{cccc} & \text { CSP_F1 } & \text { DTT30/Deg F } & \text { CSP_TEMP } \\ \text { A212B CMM Test Reactor Data } & 3.5 \mathrm{E}+18 & 175 & 464 \\ >400 F \&<520 \mathrm{~F} & 6.6 \mathrm{E}+18 & 180 & 400 \\ & 6.6 \mathrm{E}+18 & 200 & 450 \\ 2.6 \mathrm{E}+19 & 305 & 430 \\ 2.2 \mathrm{E}+19 & 210 & 510 \\ 1.58 \mathrm{E}+19 & 230 & 490 \\ 2.9 \mathrm{E}+19 & 250 & 500 \\ 3.9 \mathrm{E}+18 & 120 & 520 \\ 1.1 \mathrm{E}+18 & 70 & 495 \\ 1.5 \mathrm{E}+20 & 360 & 495\end{array}$

Ref: ASTM DS54, Radiation Effects Information Generated on the ASTM Reference Correlation-Monitor Steels, 1974.

\subsection{Comparison of Embrittlement Trends between New Data and A212B CMM Data}

In Fig. 7, several trend curves were generated, including A212B CMM test reactor data with irradiation temperature less than $300^{\circ} \mathrm{F}$ and with mean irradiation temperature of $475^{\circ} \mathrm{F}$, respectively. These trend curves indicate that the trend curve from Porter's data (w/ the adjusted high dose data) still has the lowest embrittlement rate compared to others, even though Porter's data have the lowest irradiation temperature. It is interesting to note that the trend curve from the sub-size Porter data has a similar slope as that of the Hawthorne A212B data but with much less embrittlement shift, while both data sets were irradiated $\sim 200^{\circ} \mathrm{F}$. Both of the above two trend 
curves have steeper slopes than that of the other $\mathrm{A} 212 \mathrm{~B}$ CMM test reactor data with $\sim 300^{\circ} \mathrm{F}$ or $475^{\circ} \mathrm{F}$ irradiation temperatures.

The sub-size Charpy impact specimens used for the 17 data points are much smaller than the standard Charpy specimen. Consequently there is less constraint during fracture, and the reported NDTT shifts are lower than would be expected from full-size specimens. Trudeau [12] at Chalk River and Hawthorne [13] of NRL have concluded that it is not possible to correlate the results obtained using sub-size impact specimens with standard Charpy V-notch specimens or with drop-weight determination of NDTT temperature. Furthermore, this may also apply to the A212B shift data as indicated by these sub-size specimen data, which show much less embrittlement rate compared to the full-size specimen data.

Therefore, the inconsistencies due to the A212B baseline material processes, test specimens preparations, and the consideration of the specimen size effect, the decision was made to exclude these 17 data points from developing the low temperature RPV steel embrittlement trend curve.

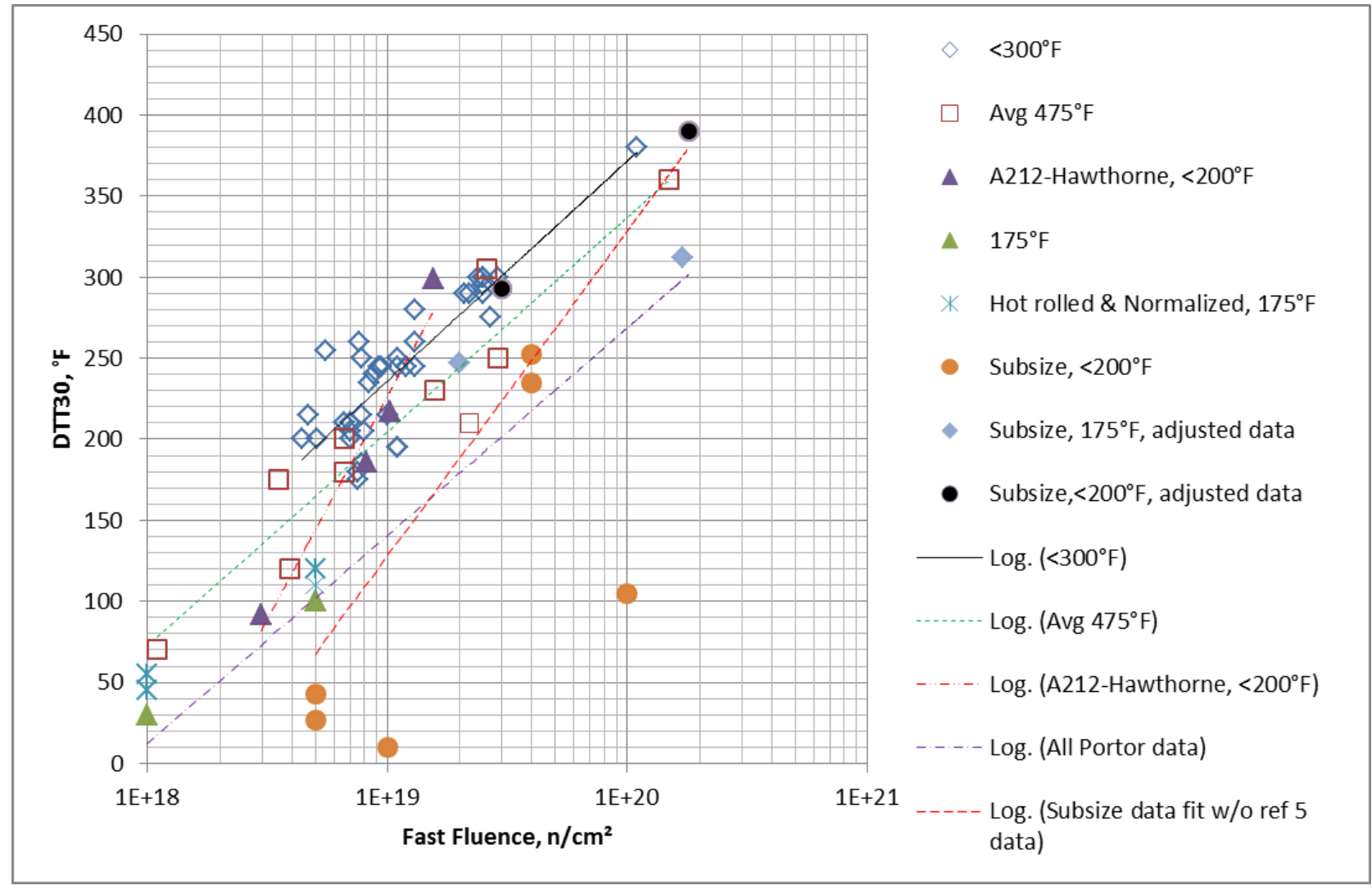

Figure 7 The embrittlement trend curves of test reactor data from A212B CMM data, Hawthorne A212B data, and the updated/adjusted A212B Porter data. All the data shown in the figure are standard Charpy samples, except noted in the figure legends. 


\section{TASK 3: The Adjustment of NDTT Shifts for A212B CMM Test Reactor Data}

The objective of this task is to adjust Charpy NDTT shifts for A212B CMM test reactor data, which were irradiated at higher temperature compared to that of HFIR RPV surveillance data.

\subsection{Irradiation Temperature Effect}

The irradiation-temperature effect on reactor pressure vessel steels is fairly well known at temperatures higher than that for the HFIR RPV. This is also demonstrated in Fig. 8, based on earlier work of using ASTM CMM test reactor data for dose-rate and irradiation temperature effect investigations [14-15]. A significant irradiation temperature effect, i.e., a lower irradiation temperature has a higher embrittlement rate, is demonstrated in Fig. 8. In general the surveillance capsules for commercial reactors contain melt wires for monitoring specimen irradiation temperatures, except for GE BWRs. The melt-wire data normally shows a higher irradiation temperature than that of the down-comer coolant [16], which are illustrated below.

The mean irradiation temperature of PR-EDB per vendor

\begin{tabular}{lcll}
\hline Vendor & $\begin{array}{c}\text { Mean Irradiation } \\
\text { Temperature }\end{array}$ & 2 Sigma & Data Point \\
\hline Westinghouse & $578^{\circ} \mathrm{F}$ & $30^{\circ} \mathrm{F}$ & 353 \\
Babcock \& Wilcox & $608^{\circ} \mathrm{F}$ & $22^{\circ} \mathrm{F}$ & 80 \\
Combustion Engineering & $554^{\circ} \mathrm{F}$ & $10^{\circ} \mathrm{F}$ & 45 \\
General Electric & $554^{\circ} \mathrm{F}$ & $24^{\circ} \mathrm{F}$ & 101 \\
\hline
\end{tabular}

It is noted here that for typical PWR and BWR the designed coolant inlet temperature is at $550^{\circ} \mathrm{F}$. Furthermore, GE BWR surveillance capsules do not contain thermal monitors, and all the BWR surveillance capsule temperature were all assumed to be at $550^{\circ} \mathrm{F}$.

Some of these temperatures may well be the transient temperatures; nevertheless, the melt wire registers the highest temperature experienced by the surveillance capsules and the associated surveillance specimens. Based on the author's experience, for surveillance data, significant deviations of the measured shift from the trend curve (i.e., more or less than $34^{\circ} \mathrm{F}$ for plate materials) should be considered as a warning flag pointing to a possible anomalous capsule environment. The most likely reason for deviations from the trend curve is the capsule temperature. Fluence and flux can be determined fairly accurately, and possible effects from these sources are relatively small in a power reactor environment. A quantitative relation between irradiation temperature and $\Delta \mathrm{T} 30$ has been established in the past [14-16], based on the nominal capsule temperature determined by the melt wires loaded in the irradiation capsule. The results show that the weld materials are the most sensitive and the forging materials are the least sensitive to the irradiation temperature.

Moreover, Based on the irradiation temperature studies [14,17], approximate calculations of the temperature increase due to gamma heating in a surveillance capsule were performed for the two-loop Westinghouse plant. The capsule was located in the downcomer and was mounted on the outer side of the thermal shield. The gamma-induced heat source obtained from the calculated gamma field was $\sim 0.117 \mathrm{~W} / \mathrm{cm}^{3}$ in the capsule. The capsule had a square cross-section $(4.3 \mathrm{~cm} \times 4.3 \mathrm{~cm})$. The maximum increase of the temperature of the specimens occurred at the center of the capsule and was calculated to be $\sim 0.6^{\circ} \mathrm{C}$, if specimens were in good thermal contact with the surveillance capsule. In the case where an air gap was assumed between the capsule and 
the specimens, the increases in the temperature at the center were $\sim 3^{\circ} \mathrm{C}, 12^{\circ} \mathrm{C}$, and $25^{\circ} \mathrm{C}$ for gap thicknesses of $0.1 \mathrm{~mm}, 0.5 \mathrm{~mm}$ and $1.0 \mathrm{~mm}$, respectively. Note that it was assumed that the gap completely separates the specimens from the capsule (e.g., there is gap between the capsule and the specimens on all sides of the specimens), which is certainly the most severe case.

Furthermore, based on an author's earlier study, due to irradiation environment the BWR data indeed showed different trend compared to the PWR data. By separating BWR data and PWR data in developing Power Reactor Pressure Vessel Steel Trend Curves, significant reductions were achieved in the uncertainty bounds for both PWR and BWR RPV embrittlement trend curves developments [18-19].

Therefore, on the issue regarding irradiation temperature for the surveillance specimens, a more thorough investigation needs to be done based on detailed neutronic and thermomechanical analysis for specific capsule design and specimen loading configuration. A more detailed discussion is provided in the Specimen irradiation temperature investigation chapter.

Earlier work by R. K. Williams [20] indicates that the thermal resistivity is seems to be insensitive to the irradiation damage to the A533B1 RPV steel. However, crystalline materials may be disordered by fast neutron bombardment. Significant effects are a pronounced decrease in the thermal conductivity and discoloration [21].Moreover, the thermal resistivity increase due to radiation damage to ceramics and graphite materials can be generally observed [22-25]. Furthermore, thermal conductivity degradation of ceramic materials due to low temperature, low dose neutron irradiation was also provided in reference 25.

Therefore, regarding the concern of oxide built-up (which is also an effective thermal barrier) on the capsule wall and potential further increase on oxide's thermal resistivity due to radiation damage, in addition to the geometry constraint and thermal conductivity of the surveillance capsule system, it would be prudent to have melt wires installed in the surveillance capsule to monitor the capsule irradiation temperatures, especially for an surveillance capsule that contains the long term aging data (high dose surveillance data). Another plot from Ref. 17, Fig. 9, provides the temperature dependent embrittlement trend of Charpy impact shift data vs. irradiation temperature that cover the temperature range from $50^{\circ} \mathrm{C}$ to $350^{\circ} \mathrm{C}$; which provides effective means and initial guidance regarding the uncertainty bands in the low irradiation temperature ranges. 


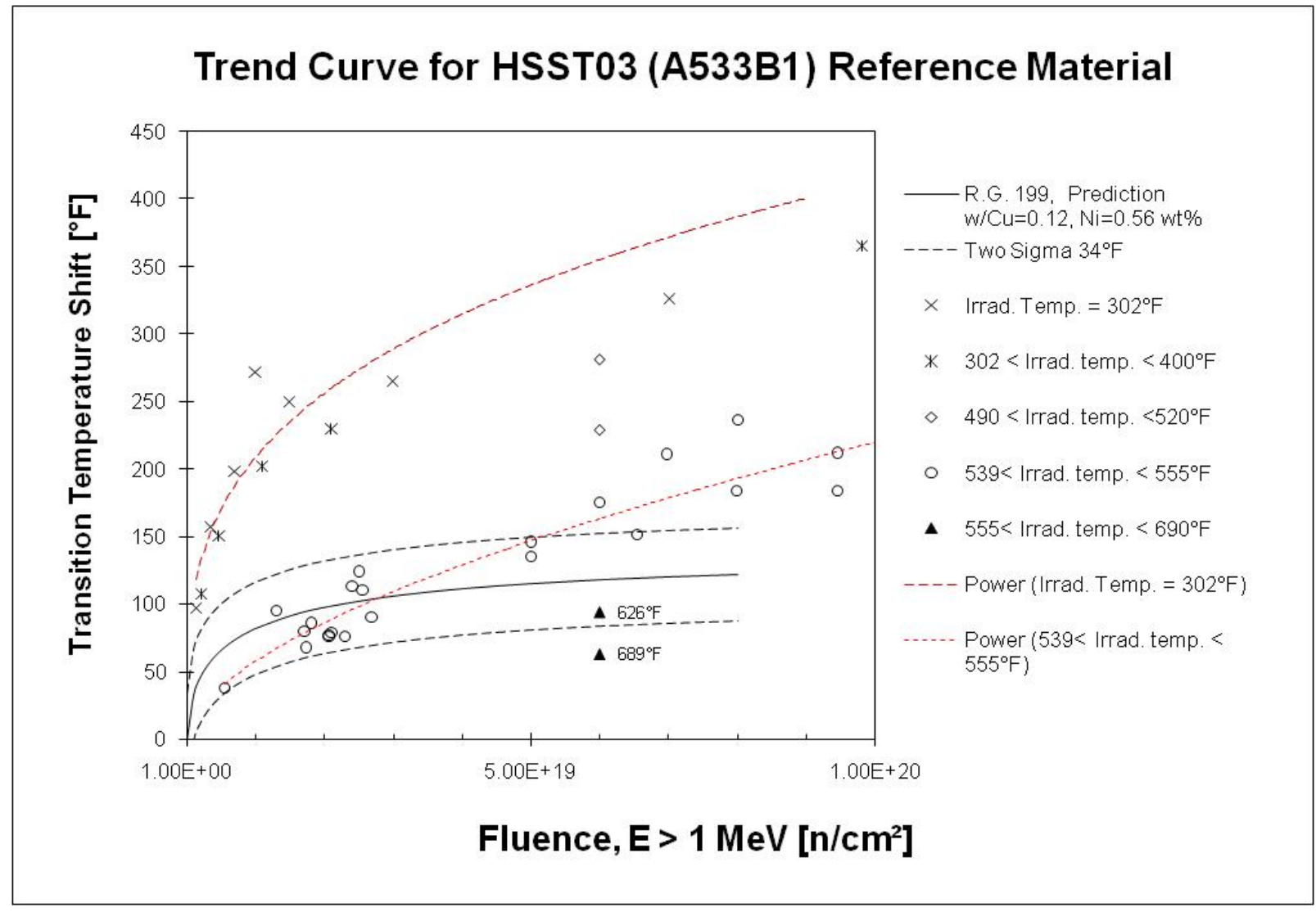

Figure 8 Irradiation temperature effect demonstrated by HSST03 CMM materials. 


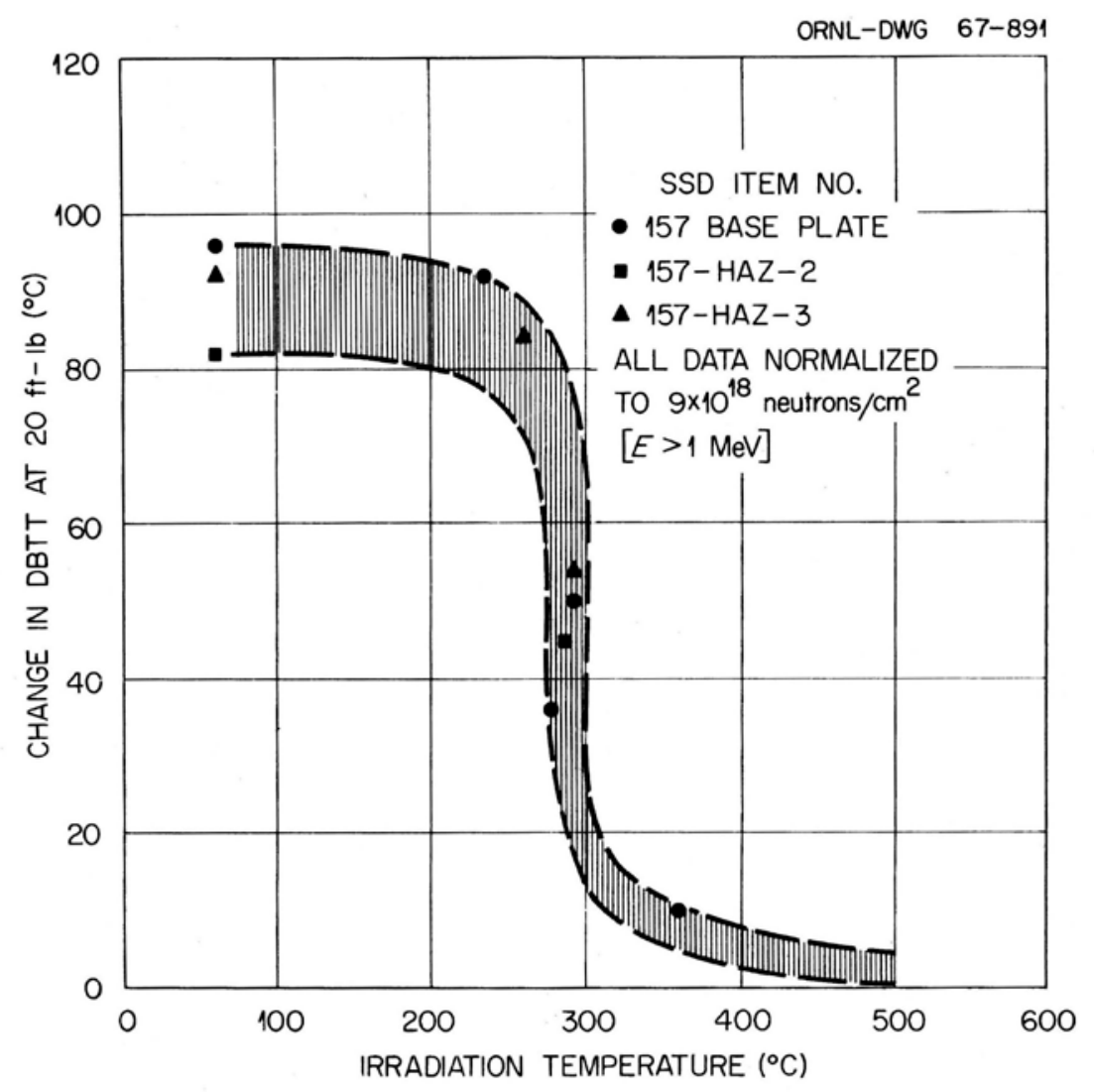

Figure 9 Effect of Irradiation Temperature on Charpy Transition Increase of A212B Steel.

\subsection{The Shift Adjustments of A212B CMM Data to Project Embrittlement at Lower Temperatures}

The trend curves of the A212B CMM test reactor data are shown in Fig. 10. They indicate that the trend curves of $150^{\circ} \mathrm{C}\left(300^{\circ} \mathrm{F}\right)$ and $246^{\circ} \mathrm{C}\left(475^{\circ} \mathrm{F}\right)$ irradiation temperatures have about the same slope (shift vs. dose). The upward shift of $150^{\circ} \mathrm{C}^{\prime}$ s trend curve to that of $246^{\circ} \mathrm{C}$ 's trend curve, at a fast fluence level of $1.0 \mathrm{E}+19 \mathrm{n} / \mathrm{cm}^{2}$, is determined to be $17.4^{\circ} \mathrm{C}\left(31.4^{\circ} \mathrm{F}\right)$. This represents an increase of $17.4^{\circ} \mathrm{C}$ of NDTT shift per $96^{\circ} \mathrm{C}$ decrease in irradiation temperature. Coincidently, this value is fairly close to that of the band of lower temperature trend curve shown in Fig. 9. Thus, an increase of $17.4^{\circ} \mathrm{C}$ will be applied to A212B CMM test reactor data that has $150^{\circ} \mathrm{C}$ irradiation temperature, to project to the HFIR irradiation environment $\left(50^{\circ} \mathrm{C}\right.$ irradiation temperature). Here, a linear relationship of NDTT shift vs. irradiation temperature is assumed. The test reactor data adjusted for an irradiation temperature of $50^{\circ} \mathrm{C}$ are shown in Fig. 11. The details of the adjusted test reactor data are shown in the spreadsheet, Low-irradiation temperature-trend-curve.xlsx. The adjusted A212B CMM test reactor data and Hawthorne's A212B data are stated in Tables 8 and 9, respectively. 
Table 8 The adjusted A212B test reactor data, to project temperature from $150^{\circ} \mathrm{C}$ to $50^{\circ} \mathrm{C}$

Adjust test A212B
CMM Test
Reactor data
$\left(150^{\circ} \mathrm{C}\right)$ to
$50^{\circ} \mathrm{C} / \mathrm{HFIR}$
Adjustment
$17.4^{\circ} \mathrm{C}$

$\begin{array}{llll}\text { CSPEF1 } & \text { DPA } & \text { DPAET } & \text { DTTX } \\ 7.60 \mathrm{E}+18 & 1.06 \mathrm{E}-02 & 1.06 \mathrm{E}-02 & 161.4 \\ & & & \\ 5.50 \mathrm{E}+18 & 7.70 \mathrm{E}-03 & 7.70 \mathrm{E}-03 & 159.4 \\ 7.80 \mathrm{E}+18 & 1.08 \mathrm{E}-02 & 1.08 \mathrm{E}-02 & 156.4 \\ 4.40 \mathrm{E}+18 & 6.10 \mathrm{E}-03 & 6.10 \mathrm{E}-03 & 128.4 \\ 4.70 \mathrm{E}+18 & 6.50 \mathrm{E}-03 & 6.50 \mathrm{E}-03 & 136.4 \\ 5.10 \mathrm{E}+18 & 7.10 \mathrm{E}-03 & 7.10 \mathrm{E}-03 & 128.4 \\ 8.40 \mathrm{E}+18 & 1.17 \mathrm{E}-02 & 1.17 \mathrm{E}-02 & 148.4 \\ 8.80 \mathrm{E}+18 & 1.22 \mathrm{E}-02 & 1.22 \mathrm{E}-02 & 150.4 \\ 9.20 \mathrm{E}+18 & 1.28 \mathrm{E}-02 & 1.28 \mathrm{E}-02 & 153.4 \\ 2.40 \mathrm{E}+19 & 3.34 \mathrm{E}-02 & 3.34 \mathrm{E}-02 & 184.4 \\ 2.50 \mathrm{E}+19 & 3.48 \mathrm{E}-02 & 3.48 \mathrm{E}-02 & 184.4 \\ 2.50 \mathrm{E}+19 & 3.48 \mathrm{E}-02 & 3.48 \mathrm{E}-02 & 184.4 \\ 7.80 \mathrm{E}+18 & 1.08 \mathrm{E}-02 & 1.08 \mathrm{E}-02 & 120.4 \\ 6.60 \mathrm{E}+18 & 9.20 \mathrm{E}-03 & 9.20 \mathrm{E}-03 & 134.4 \\ 2.50 \mathrm{E}+19 & 3.48 \mathrm{E}-02 & 3.48 \mathrm{E}-02 & 181.4 \\ 2.10 \mathrm{E}+19 & 2.92 \mathrm{E}-02 & 2.92 \mathrm{E}-02 & 178.4 \\ 2.70 \mathrm{E}+19 & 3.75 \mathrm{E}-02 & 3.75 \mathrm{E}-02 & 170.4 \\ 2.90 \mathrm{E}+19 & 4.03 \mathrm{E}-02 & 4.03 \mathrm{E}-02 & 184.4 \\ 1.30 \mathrm{E}+19 & 1.81 \mathrm{E}-02 & 1.81 \mathrm{E}-02 & 153.4 \\ 1.10 \mathrm{E}+19 & 1.53 \mathrm{E}-02 & 1.53 \mathrm{E}-02 & 125.4 \\ 1.10 \mathrm{E}+19 & 1.53 \mathrm{E}-02 & 1.53 \mathrm{E}-02 & 125.4 \\ 7.00 \mathrm{E}+18 & 9.70 \mathrm{E}-03 & 9.70 \mathrm{E}-03 & 128.4 \\ 7.00 \mathrm{E}+18 & 9.70 \mathrm{E}-03 & 9.70 \mathrm{E}-03 & 134.4 \\ 7.00 \mathrm{E}+18 & 9.70 \mathrm{E}-03 & 9.70 \mathrm{E}-03 & 131.4 \\ 7.80 \mathrm{E}+18 & 1.08 \mathrm{E}-02 & 1.08 \mathrm{E}-02 & 136.4 \\ 1.10 \mathrm{E}+19 & 1.53 \mathrm{E}-02 & 1.53 \mathrm{E}-02 & 153.4 \\ 1.30 \mathrm{E}+19 & 1.81 \mathrm{E}-02 & 1.81 \mathrm{E}-02 & 173.4 \\ 1.20 \mathrm{E}+19 & 1.67 \mathrm{E}-02 & 1.67 \mathrm{E}-02 & 153.4 \\ 2.50 \mathrm{E}+19 & 3.48 \mathrm{E}-02 & 3.48 \mathrm{E}-02 & 178.4 \\ 1.00 \mathrm{E}+19 & 1.39 \mathrm{E}-02 & 1.39 \mathrm{E}-02 & 136.4 \\ 7.50 \mathrm{E}+18 & 1.04 \mathrm{E}-02 & 1.04 \mathrm{E}-02 & 117.4 \\ 8.00 \mathrm{E}+18 & 1.11 \mathrm{E}-02 & 1.11 \mathrm{E}-02 & 131.4 \\ 1.10 \mathrm{E}+19 & 1.53 \mathrm{E}-02 & 1.53 \mathrm{E}-02 & 156.4 \\ 1.30 \mathrm{E}+19 & 1.81 \mathrm{E}-02 & 1.81 \mathrm{E}-02 & 161.4 \\ 2.20 \mathrm{E}+19 & 3.06 \mathrm{E}-02 & 3.06 \mathrm{E}-02 & 178.4 \\ 1.53 \mathrm{E}+20 & 2.13 \mathrm{E}-01 & 2.13 \mathrm{E}-01 & 295.4 \\ \text { 7.50E+18} & 1.04 \mathrm{E}-02 & 1.04 \mathrm{E}-02 & 114.4 \\ 9.50 \mathrm{E}+18 & 1.32 \mathrm{E}-02 & 1.32 \mathrm{E}-02 & 153.4\end{array}$


Table 9 The adjusted Hawthorne's A212B data, to project temperature from $93^{\circ} \mathrm{C}$ to $50^{\circ} \mathrm{C}$

\begin{tabular}{|c|c|c|c|c|}
\hline $\begin{array}{l}\text { Adjusted } \\
\text { Hawthorne data to }\end{array}$ & FLUENC & DPA & DTT30 & DTTX \\
\hline $\begin{array}{l}\text { Temp } \sim 50^{\circ} \mathrm{C} \\
\text { Adjustment }\end{array}$ & $1.565 E+19$ & 2.176E-02 & 311.076 & 172.8 \\
\hline $6.5^{\circ} \mathrm{C}$ & $1.026 \mathrm{E}+19$ & 1.426E-02 & 228.579 & 126.9 \\
\hline & 8.198E+18 & 1.140E-02 & 197.887 & 109.9 \\
\hline & $2.972 E+18$ & 4.130E-03 & 103.456 & 57.5 \\
\hline
\end{tabular}

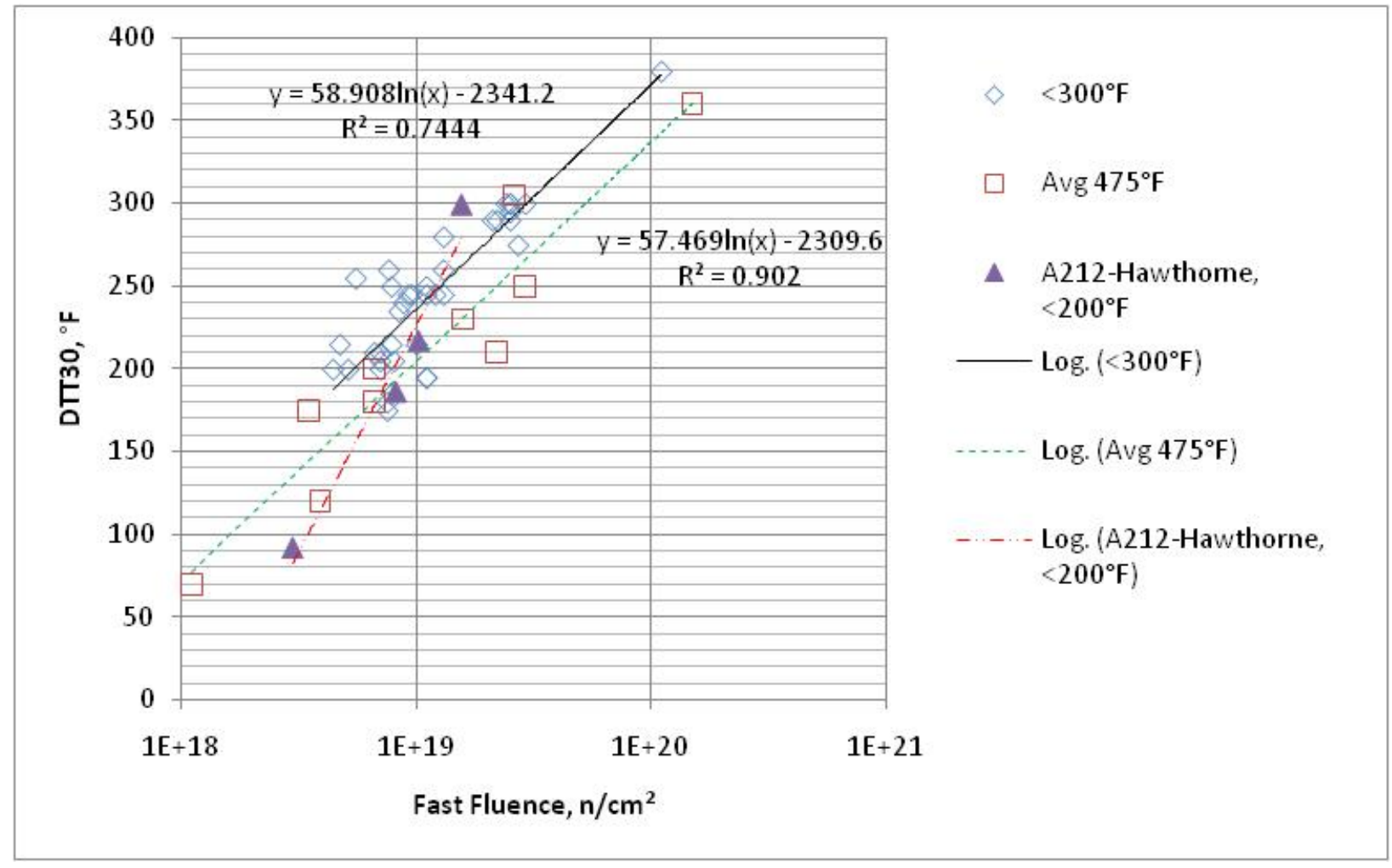

Figure 10 Comparison of irradiation temperature effect for A212B test reactor data. 


\subsection{The Low Irradiation Temperature RPV Embrittlement Trend Curve}

With the consideration of the NDTT shift's adjustment for A212B CMM test reactor data to project to an irradiation temperature of $50^{\circ} \mathrm{C}$ (data are listed in Tables 8-9), an equation for the low irradiation temperature RPV steel embrittlement trend curve was developed as described below.

$\Delta \operatorname{NDTT}\left({ }^{\circ} \mathrm{C}\right)=23.85 \log (x)^{2}+203.3 \log (x)+434.7$, with $2-\sigma$ uncertainty of $34.6^{\circ} \mathrm{C}$

where, parameter " $x$ " is referred to "total dpa."

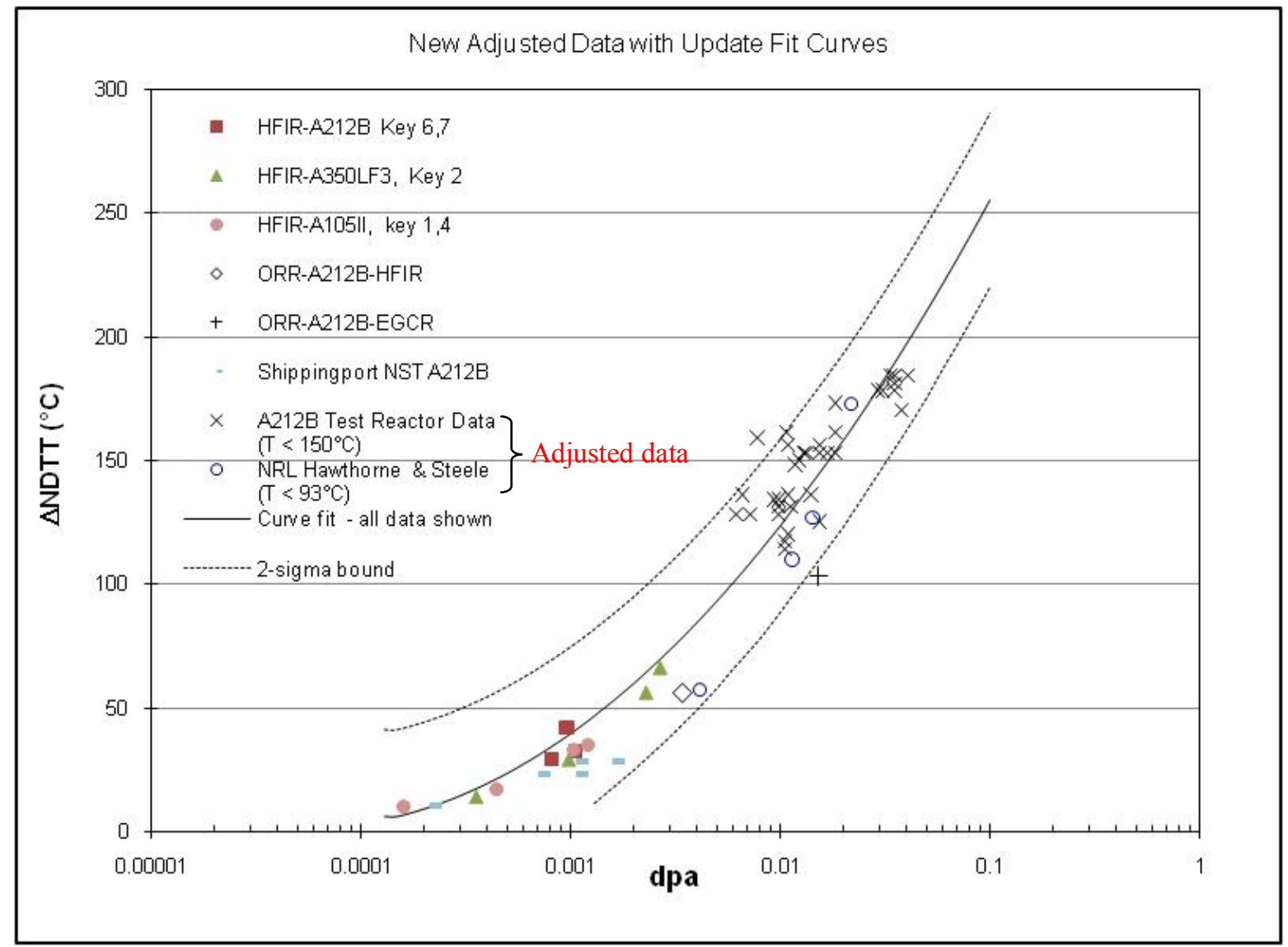

Figure 11 The low irradiation temperature RPV steels embrittlement trend curve with the consideration of irradiation temperature effect. 


\subsection{Comparison of the Low Irradiation Temperature RPV Steels Embrittlement Trend Curve with that of the 1994 Trend Curve}

The comparisons of the low irradiation temperature trend curve and the one developed in 1994 are shown in Fig. 12. It indicates that the 1994 embrittlement trend curve has a lower embrittlement rate compared to that of the new low irradiation temperature trend curve using an extended database with adjustments for irradiation temperature.

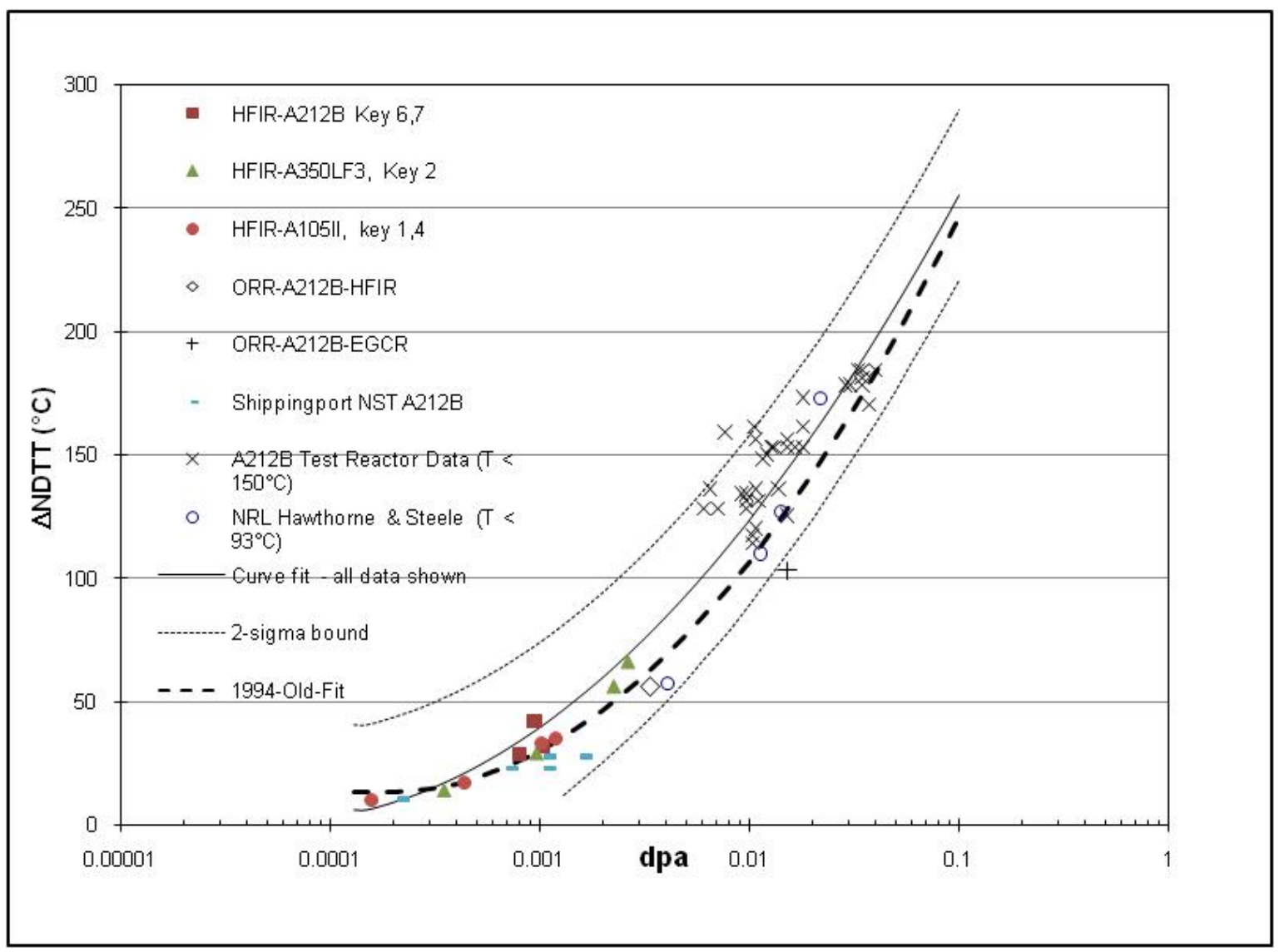

Figure 12 Comparison of the low irradiation temperature RPV embrittlement trend curve and that developed in 1994. 


\section{SURVEILLANCE SPECIMEN IRRADIATION TEMPERATURES}

The purpose of this section is to discuss the deficiency of current practice on determining the irradiation temperatures experienced by surveillance specimens in a passive surveillance capsule. A proposed study is recommended to utilize thermal monitor as control data (or other in-situ means) and neutronic gamma heating deposition as heat source, in combination with integrated thermal and mechanical analyses, including metallurgical aging consideration, to determine the temperature profiles in the irradiated surveillance capsules and the associated specimen irradiation temperature during service.

\subsection{Background}

The success of reactor technology depends critically on the choice of materials that have satisfactory resistance to radiation-induced changes in material properties. The aging and degradation of light-water-reactor pressure vessels (RPVs) are of particular concern because the magnitude of the radiation embrittlement is important to plant safety and plant operating cost. Property changes in materials due to neutron-induced displacement damage are a function of neutron flux, neutron energy, and temperature, as well as the pre-irradiation material history, material chemical composition and microstructure, since each of these influence radiationinduced microstructural evolution. These factors must be considered to reliably predict RPV embrittlement and to ensure the structural integrity of the RPV. Based on embrittlement predictions, decisions must be made concerning operating parameters, low-leakage-fuel management, possible life extension, and the potential role of pressure vessel annealing.

Temperature, neutron flux, neutron energy spectrum, and material composition and processing history all contribute to radiation embrittlement. Insufficient consideration of these conditions may result in a misleading correlation and thus incorrect predictions of material state and material behavior, as well as incorrect end-of-life determinations. A recent study [14], "Analysis of the Irradiation Data for A302B And A533B Correlation Monitor Materials" indicates that the differences in temperatures of the surveillance capsules is likely an explanation for large deviations between surveillance data and the predicted values by Nuclear Regulatory Commission's Regulatory Guide (R.G.) 1.99/2 and the draft ASTM (American Society for Testing and Materials) Standard E900-98. Currently, the draft E900-98 incorporates the coolant inlet temperature into the embrittlement model to represent the irradiation temperature of the surveillance specimens in pressurized light-water reactors. However, from the above-mentioned study [14], a large bias can still be identified for surveillance data from a higher irradiation temperature environment, and the bias is similar to that of R.G. 1.99/2. This may indicate that the coolant inlet temperature is not a good estimate of the irradiation temperature experienced by the surveillance specimens.

Temperature monitors (melting wires) within the surveillance capsules give only the upper bound and, in case of melting, do not indicate whether any high temperature was transient or sustained. Moreover, an even greater uncertainty on the capsule temperature exists for the surveillance capsules that are without thermal monitors. For example, many General Electric (GE) surveillance capsules do not contain thermal monitors. Thus, on the issue regarding irradiation temperature for the surveillance specimens, a more thorough investigation is needed based on detailed neutronic, thermal, and mechanical analysis for a specific capsule 
configuration under the specific service environment. Furthermore, the investigation on flux effect for GE boiling water reactor data can be more meaningful only if the specimen temperature can be properly estimated. Moreover, such effort can also be useful to develop protocol to assist resolving the uncertainty associated with surveillance specimen irradiation temperature effect for the long term surveillance aging data.

\subsection{Approach}

In a proposed pilot study, the author recommend to focus on the specific capsule design and the specific service environment, such as HFIR surveillance capsule and HFIR RPV environment, which will include the following two tasks.

\subsubsection{Task I: Neutronic Analysis-Calculation of energy deposition in the surveillance capsule}

The interactions of neutrons and gamma rays with material of the surveillance capsule result in energy deposition in the material and define the additional heat source, which must be known if the temperature field in the capsule is to be calculated. To determine the gamma and neutron field in the capsule a coupled neutron-gamma transport calculation is necessary. The reactor core, ex-core components (e.g. baffle, barrel, thermal shield) as well as the capsule must be included in the model. Since the secondary gamma-rays, arising from the interactions of neutrons with material outside the core may contribute considerably to the energy deposition at locations further from the core, the thermal neutron flux must be accurately calculated. This requires utilization of fine geometry mesh and neutron cross-section library with upscattering. BUGLE96 cross-section library and the computer code DORT, based on the method of discrete ordinates, which is commonly used in neutron and gamma shielding analysis will be used to perform the calculations and provide the heating rates in the surveillance capsule.

\subsubsection{Task II: Thermo-Mechanical Analysis-Evaluation of the temperature variation in the surveillance capsule}

The most accurate possible heat source value is of primary importance to make an accurate estimate of the specimen temperatures and would be determined in Task I. The specimen excess (above the coolant) temperature is determined by the internal heating and the effectiveness of the heat flow from the specimen into the coolant. Conservative thermal analyses of such assemblies can provide an upper limit estimate of the temperature and would be a starting point for this investigation. Conservative assumptions may result in high temperatures that are not realistic. A more precise estimate of the heat transfer across the gap between the container and the specimen will require accurate estimates of the contact pressure distribution, radiation heat transfer coefficients, gas condition, and the size of the gap for a specific specimen/container design and for specific operating conditions. Some of these more realistic estimates would be determined from literature searches or sensitivity studies using a thermal analysis code. The rest would be determined by performing sensitivity studies in combined thermal/stress calculations of the specimen container assembly under the internal heating conditions determined in Task I.

Similar detailed calculations on the melting wire monitor and container will be required to determine the correlation between the capsule temperature and the melting wire monitor. The internal heating of the melting wire will be determined in Task I. 
In this task, specimen temperature may be determined using the ORNL developed heat transfer code HEATING where appropriate; while commercial codes ABAQUS and PATRAN may be used for combined thermal/stress calculations.

\subsection{Issue Associated with HFIR Surveillance Capsule Temperature}

HFIR surveillance capsules are made of stainless steel (SS), the thermal conductivity of SS is typically at $16 \mathrm{~W} /\left(\mathrm{m} \mathrm{K}^{\circ}\right)$, whereas thermal conductivity of the surveillance specimen $\mathrm{A} 212 \mathrm{~B}$ steel is $\sim 40 \mathrm{~W} /\left(\mathrm{m} \mathrm{K}^{\circ}\right)$. The decreased thermal conductivity from specimen to SS wall is readily to generate thermal gradient in the surveillance capsule. Moreover, typical thermal conductivity of water is at $0.58 \mathrm{~W} /\left(\mathrm{m} \mathrm{K}^{\circ}\right)$, if gap exists in a surveillance capsule, this will further reduce the thermal conductivity of the surveillance capsule system, as discussed in Reference 14. Thus, it is expected that there would be sufficient temperature gradient exists within a surveillance capsule, that certainly will delay the deposited gamma heating in the surveillance specimens to be transferred to the water coolant boundary. Such phenomenon can be analogous to a green house effect and eventually will gradually increase the specimen temperature until the gamma heating energy dissipation balance with the capsule environment. The above consequence will be the higher specimen irradiation temperature compared to the surrounding coolant temperature.

The pressure of coolant media in HFIR around surveillance can be assumed as 468 psi, this pressure may not be sufficient to collapse the capsule SS wall to provide better contact between capsule wall and surveillance specimen. Furthermore, from the author's work on developing methodology to estimate the effective lifetime of the high voltage power line conductorconnector system (MELCOT System) operated at high temperature, it is learned that gap density (indicating the degree of degradation) will continue to increase in a conductor-connector system under thermal cycling. The consequence of this gap density increase is the increase of electrical resistance and thermal resistivity as well. The consequence of temperature rise is the primary root cause of failure in such system. This work explained the myth of increasing failure frequency of conductor-connector system in recent years due to increase in the power demand, which won a 2009 R\&D 100 Award [26-27]. There is striking similarity between this earlier work and that of surveillance capsule regarding the gap density in the tubing system.

Furthermore, due to thermal expansion mismatch between SS and steel, for instance, the thermal expansion coefficient of SS is about 1.5 times to that of carbon steel; this will certainly increase the gap between capsule wall and surveillance specimens. Furthermore, based on with the MELCOT experience, the inner radius of any tubing under thermal cycling or long term thermal aging will result in the increase of inner diameter. Thus, this will further increase the capsule system thermal resistivity.

All the above scenarios can be quantitatively investigated through the proposed specimen irradiation investigation project. 


\section{SMALL SPECIMEN TECHNOLOGY IN APPLYING TO REACTOR RPV SURVEILLANCE}

\subsection{Background}

Test methods that are currently used in the power-reactor pressure-vessel surveillance programs to evaluate the change of fracture toughness of structural steels are based on Charpy V-notch impact energy and not based on the fracture mechanics theory. This is because the size of specimen required to achieve the plane strain condition at the crack tip is prohibitively large. Hence, $\mathrm{K}_{\mathrm{IC}}$ must be inferred from data obtained from non-fracture mechanics-based test methods. If $\mathrm{K}_{\mathrm{IC}}$ values can be determined directly from a rigorous test method, the uncertainty and safety factors mandated in current regulations on the safety assessment of the material property can be relaxed and rationally justified. Besides, a significant economic savings is contemplated from the lifetime extension of aging components.

No pressure vessels and piping systems, nuclear or non-nuclear, can be constructed devoid of weldments. Thus, three material structures exist, namely, base metal, weld metal, and heataffected zone (HAZ). In existing safety surveillance programs, the states of health in all three types of materials bear equal importance in the evaluation of structural integrity. However, HAZ materials are often treated differently from the others or even excluded in the final phase of the integrity evaluation. The exclusion of HAZ material data in the evaluation of vessel integrity is due to the lack of an effective means to analyze the HAZ surveillance data, which often show inconclusive. The severity of data scatter for the HAZ metals is attributed to metallurgical heterogeneity inherent in the HAZ.

Difficulties in testing of heat-affected zone (HAZ) and interpreting precarious test data have frustrated researchers to derive meaningful fracture toughness data. The accurate determination of HAZ toughness will be immensely helpful to understand material degradation or annealing recovery occurring in the course of service. Knowing chronological changes in HAZ toughness property will lead to effective control and improve HAZ material properties through proper processing and post-weld heat treatment. Adequate test techniques to measure the $\mathrm{K}_{\mathrm{IC}}$ of complex HAZ materials do not exist and are clearly in need.

Tensile fracture (Mode I) is often considered as a major rupture failure mode. However, it has been known that rupture failure in a mixed mode of Modes I and III may be more critical compared to Mode I for ductile materials. Vessels and piping are most likely subjected to combined flexural normal stress and twisting shear stress. Little is known at this time that changes of rupture mode from Mode I to a critical mixed mode may be possible due to the service environment. Therefore, the combined impact of flexural normal stress (Mode I fracture) and the torsion shear stress (Mode III fracture, out-of-plane loading) to the fracture toughness of the materials used in the structural hardware must be reassessed.

Periodic evaluation of fracture toughness on aging component materials is an effective and prudent approach to warrant the structural integrity. This requires a large supply of specimens to support the long-term surveillance program. Therefore, substandard-size specimens are desirable to make the best use of available material and attain high penetration of hydrogen into the specimens. 


\subsection{The "Local Approach" to Cleavage Fracture}

Single-parameter fracture mechanics describes the fracture toughness of a material by global parameter, such as the stress intensity factor or the crack tip opening displacement. An alternative approach for the description of fracture is the application of a local fracture toughness criterion, based on the micromechanism of fracture event; it assumes that fracture takes place if a critical stress or strain state is reached in the vicinity of the flaw. This methodology for the prediction of fracture is known as the "Local Approach." In recent year, the Local Approach has been applied to cleavage fracture arena, and apparently it is a valuable tool for predicting lower shelf fracture behavior of structures using simple laboratory tests.

\subsection{Local Approach in Application to Master Curve Application}

Based on a weakest link micro-mechanical model by Slatcher, one assumes a non-uniformly stressed reference volume, $\mathrm{V}$, containing V/Vo elements of unit volume Vo. It is assume that the failure of one element will trigger failure of the whole body and that the elements are independent. Then the survival probability, (1-Pf), of the non-uniform stress body is given by the product of the survival probabilities of the element. A distribution function is needed to be assumed with appropriate fitting parameter to develop failure probability. Normally, it is in the form of the following:

For uniformly stressed bodies,

$\mathrm{Pf}=1-\exp \left[-\mathrm{V} / \mathrm{Vo}\left(\sigma_{1} / \sigma_{\mathrm{u}}\right)^{\mathrm{m}}\right]$

For non-uniformly stress bodies,

$\operatorname{Pf}=1-\exp \left[(-1 / \mathrm{Vo}) \Sigma_{\mathrm{j}} \mathrm{V}_{\mathrm{j}}\left(\sigma_{1, \mathrm{j}} / \sigma_{\mathrm{u}}\right)^{\mathrm{m}}\right]$

Where $\mathrm{Vj}$ is the volume of an element within which $\sigma_{1, j}$ is the principal stress and approximately constant. As cleavage fracture is initiated by dislocation slip, the summation is carried over the plastic zone size.

With the definition of Weibull stress, it can be expressed as

$\sigma_{\mathrm{w}}^{\mathrm{m}}=1 / \mathrm{Vo} \int \sigma^{\mathrm{m}}{ }_{1, \mathrm{j}} \mathrm{dVp}$

The local criterion deduced in the above can be used to predict the fracture toughness of cracking component if the stresses and strains ahead of the crack tip and the material properties are known. For symmetric mode I loading under small scale yielding, the stress distribution ahead of the crack tip can be expressed with Hutchinson, Rice, Rosengren (HRR) field

$\sigma_{\mathrm{ij}}(\theta, \mathrm{r})=\sigma_{\mathrm{y}} f\left[\mathrm{r} /\left(\mathrm{K}_{\mathrm{I}} / \sigma_{\mathrm{y}}\right)^{2}, \mathrm{~N}\right] \mathrm{g}_{\mathrm{i}, \mathrm{j}}(\theta, \mathrm{N})$

and, the Weibull stress can be written as

$\sigma_{\mathrm{w}}{ }^{\mathrm{m}}=1 / \mathrm{Vo} \iiint^{\mathrm{m}}{ }_{1, \mathrm{j}} \mathrm{dr} \mathrm{dz} \mathrm{rd} \theta$,

if one assume that $\mathrm{K}_{\mathrm{I}}$ is uniform along the crack front, (i.e. assume uniform stress-strain field throughout the thickness of the tested sample), the Weibull stress can be written as

$\sigma_{\mathrm{w}}^{\mathrm{m}}=\sigma \mathrm{y}^{(\mathrm{m}-4)} \mathrm{K}_{\mathrm{I}}^{4} \mathrm{~B} \mathrm{Q}(\mathrm{N}, \mathrm{m}) / \mathrm{Vo}$;

Eventually, we reach the final term of

$\mathrm{Pf}=1-\exp \left[-\right.$ Constant $\left.\mathrm{B} \mathrm{K}_{\mathrm{I}}^{4}\right]$, 
This formula is often used in material research, including Master Curve Program Development.

However, such "Local Approach" clearly indicates that for a complex material structure, or nonuniform stress distribution fields exist in the tested samples, more elaborated or detailed finite element analyses are needed to provide more detailed stress/strain distributions to come up with a more representative Weibull stress distribution, instead of a simplified expression used in the above. For instance, it is well-known, for a miniature specimen there exists a large stress-strain gradient profile throughout the specimen thickness, thus, it cannot assume that the $\mathrm{K}_{\mathrm{I}}$ or the associated plastic process zone are constants throughout the specimen thickness. This in term will result in a different formulation w.r.t the typical Pf formulation mentioned above.

Furthermore, for subsize PCCV sample used for developing master curve, from Yamamoto and Odette's works, they introduced additional constraints or modification factors to cope with the concern of the size effect. It is not clear whether ORNL master curve developed data also taking into account of such correction factors to mitigate the size effect.

Indeed, the methodology for cleavage fracture is a valuable tool to predict lower shelf fracture behavior of structure using simple laboratory tests. However, the method requires accurate numerical analysis of the stress/strain state in the flawed structure; such as weldment residual stress and other microstructure variation. Moreover, the material parameters of the local approach are microstructure dependent. This also makes the application to weldments, which exhibit steep microstructure gradients, more difficult. Furthermore, the localized plastic deformation introduce significant stress/strain gradient within a small or miniature specimen also result in significant potential bias and error in applying Local Approach. Therefore, further work is needed to enhance the reliability of the method and to uncover the limitations before the Local Approach can be used as an alternative fracture assessment procedure.

\subsection{Spiral Notch Torsion Fracture Toughness Test and Its Application to Small Specimens and Mixed-Mode Failure Investigation}

Despite the international efforts on the development of small specimen testing techniques, no methods currently exist for direct measurement of $\mathrm{K}_{\mathrm{IC}}$ for small specimens without a concern for size effect. Operation of the SNTT System conforms to classical fracture mechanics theory. In contrast the $\mathrm{K}_{\mathrm{IC}}$ data currently used to set toughness safety margins for nuclear and nonnuclear pressure vessels are frequently inferred from results of the Charpy V-notch test. The inferred data inevitably contain large uncertainties; therefore, large safety factors must be incorporated into component designs.

The compact tension (CT) specimen has been widely used in existing fracture toughness test methods because the general consensus indicates it is the next-best basic configuration that nearly conforms to the strict requirements of the classical theory of fracture mechanics. Despite the simplification, the theoretical conditions (i.e., the conditions required to achieve uniformly distributed applied stress over the thickness and plane-strain condition) can never materialize as long as the free surfaces exist at both ends. The size effects will be further amplified when the thickness decreases to a thin plate. Another dilemma is that an increase in specimen thickness will automatically accompany an increase in specimen length and width in order to maintain specimen rigidity under load. 
The problems discussed in preceding sections can now be resolved using the alternative method recently developed at the Oak Ridge National Laboratory for determining $\mathrm{K}_{\mathrm{IC}}$ of structural materials based on the fracture mechanics theory.

The Spiral Notch Torsion Test (SNTT) system measures the intrinsic fracture toughness $\left(K_{\mathrm{IC}}\right)$ of structural materials, overcomes many of the limitations inherent in traditional techniques, and introduces new possibilities for standardizing fracture toughness testing. The SNTT technology [28-43] won a R\&D 100 Award in 2002 for its contribution to the advance of the fracture mechanics. The system is uniquely suited to test a wide variety of materials, such as metals and alloys, ceramics, composites, polymers, carbon foam, and concrete; and recently, SNTT has extended to polymeric composite, thin-film coating interface toughness investigation. The SNTT system operates by applying pure torsion to cylindrical specimens machined with a notch line that spirals around the specimen at a $45^{\circ}$ pitch. The $\mathrm{K}_{\mathrm{IC}}$ values are obtained with the aid of a three-dimensional finite-element computer code, TOR3D-KIC.

The SNTT miniaturization capability has also been demonstrated to A533B pressure vessel steel, as illustrated by the sample on the right hand side in Figure 13. This miniaturization SNTT sample was originally from a tensile surveillance specimen, where the spiral notch was added accordingly to convert it into a SNTT fracture toughness specimen. Because of the plane strain and axisymmetric constraint, and the uniformity in the stress and strain fields in a SNTT system, the crack front must propagate perpendicularly toward the specimen axis along the conoids. Postmortem examination verified the crack propagation behavior (see Figure 14). It also clearly indicates a uniform fatigue precrack growth.

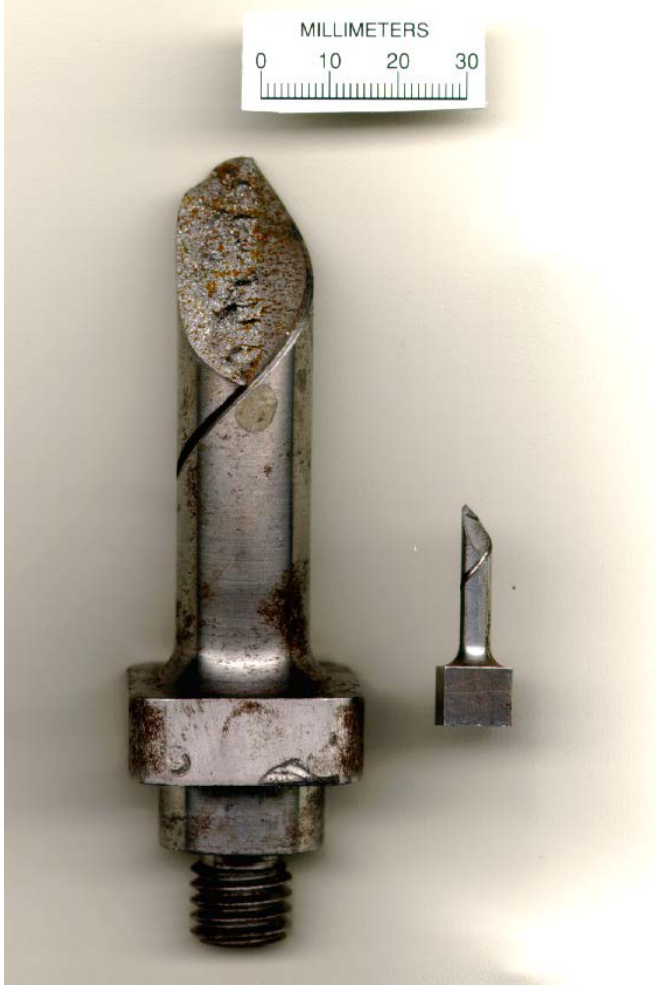

Figure 14 Tested SNTT metal specimens (A533B1) showing specimen miniaturization.



Figure 13 Fractured 7475-T7351 aluminum SNTT sample reveals uniform crack front. 
When a lobe of $\mathrm{V}$-grooved spiral line with a $45^{\circ}$ pitch is machined on the surface of the specimen, the grooved line effectively becomes a Mode I crack mouth opening. Examination reveals that the rod specimen is a different manifestation of a CT specimen having a thickness equivalent to the full length of the spiral line.

In real structures fracture failure seldom occurs in a single mode, such as mode I in pure tension. In many pressure vessel and piping systems, while these components are effective in providing system flexibility to mitigate flexural loading (mode I loading), they also create torsional load (shear load known as mode III loading) to the systems, such as U-bend tube or other out-of-plane loading conditions. In a recent work done by Gelles [44], for ductile metals at a critical angle, the mixed-mode (Mode I+ Mode III) fracture toughness can be reduced to $50 \%$ of that of Mode I alone. Fracture behaviors under mixed mode loading (modes I and III) of many structural materials are not well known partially due to the experimental difficulties with the test method using a CT specimen. The SNTT method has a significant advantage over the conventional methods to accomplish mixed mode fracture toughness testing by either using different pitch angle of the spiral groove or applying various combinations of loads in tension and torsion to the standard specimen.

SNTT Technology has been extended to pipeline steel arena. Recently ORNL completed the further enhancements of SNTT method to determine the weld fracture toughness degradation in high-pressure hydrogen environment. Based on recent testing, the weld region is recognized as most vulnerable for hydrogen embrittlement in steel hydrogen transmission pipelines. The standard testing techniques are oftentimes unreliable in evaluating the mechanical property of the weld region with highly non-uniform distribution of microstructure. Hence, the applicability of SNTT for testing weld region is a major technical advancement. Testing using the SNTT technique in air was able to quantify fracture toughness of different microstructures in the weld and base metal of high strength 4340 steel. The welding-induced microstructure change resulted in a reduction in fracture toughness by almost $40 \%$ compared to that of the base steel in recent work. The tested fractured SNTT Gleeble sample is shown in Figure 15.

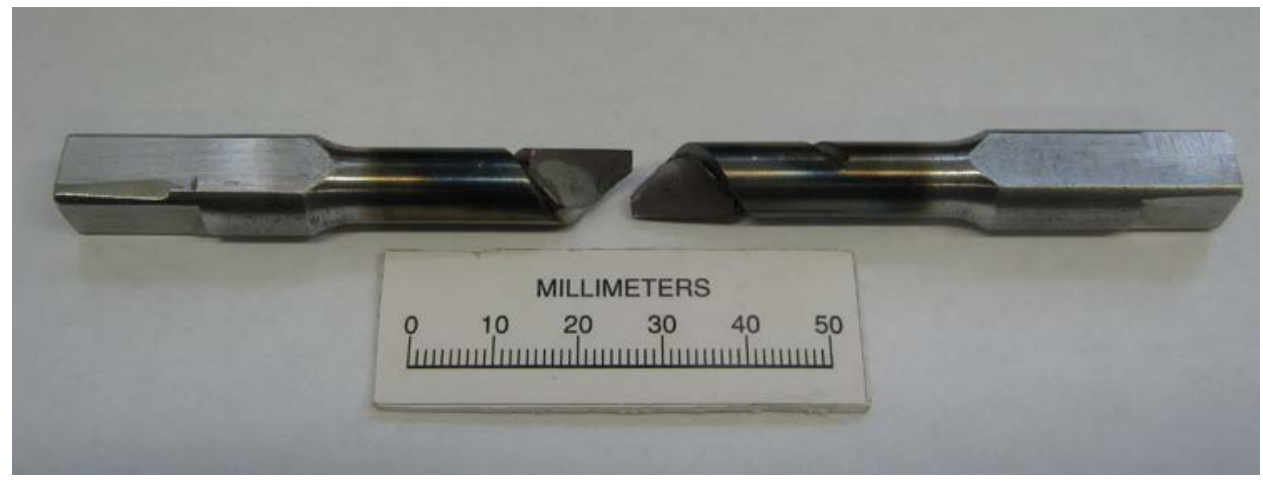

Figure 15 Fractured SNTT Gleeble samples. 


\section{CONCLUSIONS}

The main findings of this embrittlement trend curve development project are as followings:

(1) A total of 74 data points, used in the 1994 HFIR RPV steel embrittlement trend curve development, were identified. They are from three main sources, namely, (a) Hawthorne's data, (b) A212B test reactor data, and (c) HFIR RPV steel surveillance program related data. The equation of this embrittlement trend curve is given below.

$\Delta \operatorname{NDTT}\left({ }^{\circ} \mathrm{C}\right)=31.3 \log (x)^{2}+233.5 \log (x)+448.7$, with a $2-\sigma$ uncertainty of $33.4^{\circ} \mathrm{C}$, where parameter $x$ is referred to total dpa.

(2) Seventeen Charpy NDT shift data of A212B materials, with irradiation temperatures less than $93^{\circ} \mathrm{C}\left(200^{\circ} \mathrm{F}\right)$, were identified. However, these data show a significantly different trend compared to the trend revealed from the A212B CMM test reactor data. Thus, the decision was made to not include these data into the low irradiation temperature trend curve development.

(3) An increase of $17.4{ }^{\circ} \mathrm{C}$ was applied to $\mathrm{A} 212 \mathrm{~B}$ test reactor data with a $150^{\circ} \mathrm{C}$ irradiation temperature, to project to the $50^{\circ} \mathrm{C}$ HFIR irradiation temperature. A total of 59 data points was used in developing the updated embrittlement trend curve. The equation for the new low irradiation temperature RPV steel embrittlement trend curve with the consideration of the temperature adjustment is given below.

$$
\Delta \operatorname{NDTT}\left({ }^{\circ} \mathrm{C}\right)=23.85 \log (x)^{2}+203.3 \log (x)+434.7 \text {, with } 2-\sigma \text { uncertainty of } 34.6^{\circ} \mathrm{C}
$$

This RPV embrittlement trend curve has a higher embrittlement rate compared to that developed in 1994.

(4) On subject related to irradiation temperature experienced by surveillance specimen, a proposed study is recommended to utilize integrated neutronic, thermal, and mechanical analyses to quantitatively determine the temperature profiles and specimen irradiation temperature within the surveillance capsule environment during service.

(5) On subject related to utilizing small specimen technology for power reactor surveillance program, ORNL SNTT technology was recommended as an alternative testing procedure for determining the intrinsic fracture toughness of baseline and irradiated surveillance specimens.

\section{ACKNOWLEDGMENTS}

The author gratefully acknowledges Randy Nanstad, Shafik Iskander, Dan Naus, and Igor Remec for reviewing this report and Henry Kmieciak for providing financial support. This research was sponsored by the Division of Materials Sciences and Engineering, High Flux Isotope Reactor Program, U.S. Department of Energy, and was carried out under contract DE-AC05-00OR22725 with UT-Battelle, LLC. 


\section{REFERENCES}

[1] Remec, I., Wang, J. A., Kam, F. B. K., and Farrell, K., "Effects of Gamma-Induced Displacements on HFIR Pressure Vessel Materials," Journal of Nuclear Material, Volume 217 pp. 258-268, 1994.

[2] R. D. Cheverton, J. G. Merkle, and R. K. Nanstad, "Evaluation of HFIR Pressure-Vessel Integrity Considering Radiation Embrittlement," ORNL/TM-10444, April 1988.

[3] R. K. Nanstad, S. K. Iskander, A. F. Rowcliffe, W. R. Corwin and G. R. Odette, "Effects of $50^{\circ} \mathrm{C}$ Surveillance and Test Reactor Irradiations on Ferritic Pressure Vessel Steel Embrittlement," pp 5-29, Effecto of Radiation on Materials: 14th International Symposium (Volume II), ASTM STP 1046, June 27-29, 1989.

[4] O. K. Chopra, W. J. Shack, and S. T. Rosinski, NUREG/CR-5748, "Radiation Embrittlement of the Neutron Shield Tank from the Shippingport Reactor," October 1991.

[5] L.E. Steele and J. R. Hawthorne, "Effect of Irradiation Temperature on Neutron-Induced Changes in Notch Ductility of Pressure-Vessel Steels," NRL-5629, US Naval Research Laboratory Report, June, 1961.

[6] J. R. Hawthorne, "Radiation Effects Information Generated on the ASTM Reference Correlation-Monitor Steels," ASTM DS54, July, 1974.

[7] L. F. Porter, "Radiation Effects in Steel," pp. 147-195, ASTM STP No. 276, 1959.

[8] J. C. Wilson and R. G. Berggren, "Effects of Neutron Irradiation in Steels," Proceedins, ASTM, Vol. 55, p689, 1955.

[9] R. G. Berggren and J. C. Wilson, "Recent Data on the Effects of Neutron Irradiation on Structural Metals and Alloys," ORNL-CF-56-11-1, January 1957.

[10] J. C. Wilson, R. G. Berggren, F. M. Grizzel, and J. T. humphries, "HRP Raidation Metallurgy, Notch Impact Properties," ORNL-2614, August 1958.

[11] M. L. Bleiberg, Effect of Neutron Bombardment Upon the Properties of ASTM Type SA212B Steel," WAPD-T-206, October 1955.

[12] L. P. Trudeau, "Effect of Neutron Irradiation on Mechanical Properties of Ferritic Steels and Irons," Second United Nations International Conference on the Peaceful uses of Atomic Energy, A/Conf.15/P/190, Canada, September 1958.

[13] J. R. Hawthorne and L. E. Steele, "The Effect of Neutron Irradiation on the Transition Temperature Characteristics of Several Steels as Determined by Charpy-V and Drop-Weight Tests," AEC Conference on the Effect of Neutron Irradiation on the Mechanical Properties of Structural Materials, 1959.

[14] Jy-An Wang, "Analysis of the Irradiated Data for A302B and A533B Correlation Monitor Materials," Effects of Radiation on Materials: Vol.19, ASTM STP 1366, pp. 59-80, March 2000.

[15] Jy-An Wang, "Analysis of the Irradiated Data for A302B and A533B Correlation Monitor Materials," NUREG/CR-6413, ORNL/TM-13133, Nuclear Regulatory Commission, April 1996.

[16] Jy-An Wang, F. B. K. Kam, and F. W. Stallmann, "Embrittlement Data Base (EDB) and Its Applications," Effects of Radiation on Materials: 17th Volume, ASTM STP 1270, pp. 500521, August 1996.

[17] I. I. Siman-Tov, "Heat Transfer Analysis of the LWR Presure Vessel Steel Irradiation Capsules in the Oak Ridge Research Reactor-Pressure Vessel Benchmark Facility," NRUEG/CR-2053 (ORNL/TM-427), U.S. Nuclear Regulatory Commission, April 1982. 
[18] Jy-An Wang and N. S. Rao, "New Methodologies for Developing Radiation Embrittlement Models and Trend Curves of the Charpy Impact Test Data," Effects of Radiation on Materials, Vol. 21, pp.634-652, ASTM STP 1447, Journal of ASTM International, December, 2004.

[19] Jy-An Wang, N.S. Rao, S. Konduri, "The Development of Radiation Embrittlement Models for U. S. Power Reactor Pressure Vessel Steels," Journal of Nuclear Materials, V. 362 (1), pp. 116-127, 2007.

[20] R. K. Williams, R. K. Nanstad, R. S. Graves, and R. G. Berggren, "Irradiation Effects on Thermal Conductivity of a Light-Water Reactor Pressure Vessel Steel," Journal of Nuclear Materials, Vol 115, Nos. 2\&3, pp. 211-215, April 1983.

[21] R. G. Berggren, W. J. Stelzman and T. N. Jones, Radiation effects on pressure vessel steels, 1967, USAEC Report ORNL-4097.

[22] J. R. Eaton, Electrons, Neutrons and Protons in Engineering, Pergamon Press, Oxford, London, 1966.

[23] Jean-Paul Crocombettea and Laurent Proville, "Thermal Conductivity Degradation Induced by Point Defects in Irradiated Silcon Carbide," Applied Physics Letters, 98, 191905, (2011).

[24] L David, S Gom`es, G Carlot, J-P Roger, D Fournier, C Valot and M Raynaud, "Characterization of thermal conductivity degradation induced by heavy ion irradiation in ceramic materials,” J. Phys. D: Appl. Phys. 41 (2008) 035502 (11pp).

[25] L.L. Snead, S.J. Zinkle, D.P. White, "Thermal conductivity degradation of ceramic materials due to low temperature, low dose neutron irradiation," Journal of Nuclear Materials 340 (2005) 187-202.

[26] Jy-An Wang, Edgar Lara-Curzio, Thomas King, Joe Graziano, John Chan, "The Integrity of ACSR Full Tension Splice Connector at Higher Operation Temperature," IEEE Transactions on Power Delivery, Vol. 23 (2), pp. 1158-1165, (2008).

[27] John Jy-An Wang, John K. Chan, and Joseph A. Graziano, "The Lifetime Estimate for ACSR Single Stage Splice Connector Operating at Higher Temperatures," accepted by IEEE PES Power Delivery Transaction, April, 2011.

[28] Jy-An Wang and Ken Liu, "An Innovative Technique for Evaluating Fracture Toughness of Graphite Materials," Journal of Nuclear Materials Vol. 381 (2008) p.177-184.

[29] J. A. Wang and K. C. Liu, "A New Approach to Evaluate Fracture Toughness of Structural Materials," Journal of Pressure Vessel Technology, Volume 126, Issue 4, pp. 534-540, November 2004.

[30] J. A. Wang, K. C. Liu, D. E. McCabe, and S. A. David, "Using Torsion Bar Testing to Determine Fracture Toughness, $\mathrm{K}_{\mathrm{IC}}$," Journal of Fatigue \& Fracture for Engineering Materials and Structure, Vol. 23, pp 45-56, 2001.

[31] J. A. Wang, Ian G. Wright, Michael J. Lance, Ken C. Liu, "Interface Fracture Toughness Evaluation for MA956 Oxide Film," Journal of Failure Analysis and Prevention, 5(6), pp. 79-94, December, 2005.

[32] Jy-An John Wang, Ian G. Wright, Michael J. Lance, Ken C. Liu, "A New Approach for Evaluating Thin Film Interface Fracture Toughness," submitted to Material Science and Engineering Journal for consideration, February 2006.

[33] R. A. Bayles, R. K. Singh Raman, S. P. Knight, J. A. Wang, "Evaluating Stress-Corrosion Cracking Susceptibility Using a Torsion Test,” 2005 ASME Pressure Vessel Piping Conference, July 17-21, 2005, Denver, Colorado.

[34] J. A. Wang and K. C. Liu, "Fracture Toughness Determination Using Spiral-Grooved 
Cylindrical Specimen and Pure Torsional Loading," U.S. Patent.

[35] J. A. Wang, Ian G. Wright, Michael J. Lance, Ken C. Liu, "Interface Fracture Toughness Evaluation for MA956 Oxide Film," 2005 ASM International Surface Engineering Congress, August 1-3, 2005, St. Paul, Minnesota.

[36] R. A. Bayles, R. K. Singh Raman, S. P. Knight, J. A. Wang, "Evaluating Stress-Corrosion Cracking Susceptibility Using a Torsion Test," 2005 ASME Pressure Vessel Piping Conference, July 17-21, 2005, Denver, Colorado.

[37] J. A. Wang, Robert C. Singleterry Jr., Ronald J. Ellis, and Hamilton T. Hunter, "Radiation Effects on Spacecraft Structural Materials," Proceedings of International Conference on Advanced Nuclear Power Plants, June 9-13, 2002, Hollywood, Florida.

[38] J. A. Wang, K. C. Liu, and G. A. Joshi, "Using Torsion Bar Testing to Determine Fracture Toughness of Ceramic Materials," ASME Proceeding of ETCE 2002 Conference on Composite Materials Design \& Analysis, February 3-4, 2002, CMDA-29077, Houston, Texas.

[39] J. A. Wang, K. C. Liu, I. G. Wright, R. L. Xu, “An Innovative Technique For Bi-Material Interface Toughness Research,” IMECE2004, ASME International Mechanical Engineering Congress, November 13-19, 2004, Anaheim, California.

[40] Robert Bayles, Steve King, J. A. Wang, "Application of Disc Compact Tension Formulas to Compliance and K-Calibration of Spiral Notch Torsion Test Specimens," 6th International Aircraft Corrosion Workshop, August 24-27, 2004 at the Holiday Inn Select, Solomons, Maryland.

[41] R.K. Singh Raman, R. Bayles, S. Knight, Jy-An Wang, B.R.W. Hinton B.C. Muddle, "Development of Spiral Notch Torsion Test (SNTT): A New Fracture Mechanics Approach for Determination of $\mathrm{K}_{\mathrm{ISCC}}$, submitted to Environment-Induced Cracking of Metals Conf., Banff, Canada, 19-23 Sept '04.

[42] John Jy-An Wang, Ken C. Liu, and Dan Naus, "A New Test Method for Determining the Strength and Fracture Toughness of Cement Mortar and Concrete," Concrete \& Cement Research, 40 (2010), pp. 497-499, 2010.

[43] J. A. Wang, K. C. Liu, and D. E. McCabe, "An Innovative Technique for Measuring Fracture Toughness of Metallic and Ceramic Materials," Fatigue and Fracture Mechanics: 33rd Volume, ASTM STP 1417, pp. 757-770, January 2003.

[44] H-X. Li, R.H. Jones, J.P. Hirth, D.S. Gelles, Fracture toughness of the F-82H steel-effect of loading modes, hydrogen, and temperature, Journal of Nuclear Materials, 233, (o), pp. 258263, 1998. 